\title{
Anatomical Compartments in the White Matter of the Rabbit Flocculus
}

\author{
J. TAN, J.I. SIMPSON, AND J. VOOGD \\ Department of Anatomy, Erasmus University Rotterdam, 3000 DR Rotterdam, \\ The Netherlands (J.T., J.V.) and Department of Physiology and Biophysics, \\ New York University Medical Center, New York, New York 10016 (J.I.S.)
}

\begin{abstract}
The white matter of the rabbit flocculus is subdivided into five compartments by narrow sheets of densely staining acetylcholinesterase-positive fibers. The most lateral compartment is continuous with the $\mathrm{C}_{2}$ compartment of the paraflocculus and contains the posterior interposed nucleus. The other four compartments are numbered from lateral to medial as floccular compartments $1,2,3$, and $4\left(\mathrm{FC}_{1-4}\right) . \mathrm{FC}_{1-3}$ continue across the posterolateral fissure into the adjacent folium (folium $\mathrm{p}$ ) of the ventral paraflocculus. $\mathrm{FC}_{4}$ is present only in the rostral flocculus. In the caudal flocculus $\mathrm{FC}_{1}$ and $\mathrm{FC}_{3}$ abut dorsal to $\mathrm{FC}_{2}$. Fibers of $\mathrm{FC}_{1-4}$ can be traced into the lateral cerebellar nucleus and the floccular peduncle. The presence of acetylcholinesterase in the deep stratum of the molecular layer of the flocculus and ventral paraflocculus distinguishes them from the dorsal paraflocculus. The topographical relations to the flocculus and the floccular peduncle with group y and the cerebellar nuclei are discussed. 1995 Wiley-Liss, Ine.
\end{abstract}

Indexing terms: cerebellum, acetylcholinesterase, paraflocculus, vestibular nuclei, cerebellar nuclei

The subdivision of the cerebellum into longitudinal zones that extend perpendicularly to the transverse fissures and continue from one lobule to the next supplements the traditional subdivision of the cerebellum into lobes, lobules, and folia. These zones have been defined as longitudinal strips of Purkinje cells projecting to a particular cerebellar or vestibular target nucleus (Voogd, 1964, 1969; Voogd and Bigaré, 1980) or by the origin of their olivocerebellar climbing fiber afferents (Courville et al., 1974; Groenewegen and Voogd, 1977; Groenewegen et al., 1979; Brodal and Kawamura, 1980; Voogd, 1982; Bernard, 1987). A longitudinal zonal arrangement also has been demonstrated for Purkinje cells containing certain markers (Chan-Palay et al., 1981, 1982; Nilaver et al., 1982; Ingram et al., 1985; Hawkes and Leclerc, 1987) and for the distribution of certain enzymes, including acetylcholinesterase (AChE) in the molecular layer of the cerebellar cortex (Scott, 1963, 1964; Marani and Voogd, 1977).

The zonal pattern of the cerebellar cortex is expressed in the cerebellar white matter as a system of compartments that contain the efferent axons and the climbing fiber afferents of the Purkinje cells of the longitudinal zones (Voogd, 1969, 1989). These compartments can be distinguished with the Häggqvist myelin stain as bundles of rather coarse Purkinje cell fibers separated by narrow strips of thin fibers, the so-called raphes (Voogd, 1964, 1969). Since then, it has been shown that these raphes stain strongly for AChE (Hess and Voogd, 1986). The colocalization of axons of the Purkinje cells of a zone and their climbing fiber afferents in a particular white matter compartment and the cotermination of these Purkinje cell axons and the collaterals of their climbing fiber afferents in one of the cerebellar or vestibular nuclei formed the basis for the concept of the modular organization of the cerebellum (Voogd, 1969; Groenewegen and Voogd, 1977; Groenewegen et al., 1979; Voogd and Bigaré, 1980). In this concept a module consists of a discrete strip of Purkinje cells, their target nucleus, and the olivocerebellar afferents to these two structures. Anatomical and electrophysiological studies that correlated climbing fiber afferents with the output of the cerebellar cortex of the anterior lobe in the cat generally supported the modular organization of this part of the cerebellum (Voogd, 1969, 1989; Oscarsson, 1973; Andersson and Oscarsson, 1978a,b; Trott and Armstrong, $1987 \mathrm{a}, \mathrm{b})$. Three compartments were distinguished in the white matter of the paraflocculus in Häggqvist-stained sections of the cerebellum of cat and ferret (Voogd, 1964, 1969). The medial $\mathrm{C}_{2}$ compartment is related to the posterior interposed nucleus, and the lateral $D_{1}$ and $D_{2}$ compartments access different parts of the dentate nucleus. Climbing fibers from the rostral medial accessory olive (MAO) use the $\mathrm{C}_{2}$ compartment to terminate on Purkinje cells of the $\mathrm{C}_{2}$ zone; the principal olive projects to the $D_{1}$ and $D_{2}$ zones of

\footnotetext{
Accepted September 9, 1994.
}

Address reprint requests to J. Voogd, Department of Anatomy, Erasmus University Rotterdam, P.O. Box 1738, 3000 DR Rotterdam, The Netherlands. 
the paraflocculus (Groenewegen et al., 1979). Compartments in the white matter of the flocculus have until now only been observed in the cerebellum of the monkey by Hess and Voogd (1986) using AChE histochemistry.

Anatomical tracing and electrophysiological studies have shown that the afferent climbing fiber and the efferent connections of the flocculus are characterized by a zonal organization. Climbing fibers from the dorsal cap, the adjacent ventrolateral outgrowth, and the rostral medial accessory olive terminate in the flocculus in a pattern of alternating longitudinal zones (Groenewegen and Voogd, 1977; Yamamoto, 1979a; Gerrits and Voogd, 1982, 1989; Sato et al., 1983; Ruigrok et al., 1992). The climbing fiber zones distinguished by Yamamoto (1979a) in the rabbit and by Sato et al. (1983) in the cat seem to coincide with Purkinje cell zones projecting to certain vestibular and cerebellar nuclei as delineated by the same authors (Yamamoto and Shimoyama, 1977; Yamamoto, 1978; Sato et al., $1982 a, b)$. Seven and five climbing fiber zones were distinguished in the flocculus of cat (Gerrits and Voogd, 1982) and rat (Ruigrok et al., 1992), respectively.

According to Bolk (1906, see also Voogd, 1964, 1975), the paraflocculus and the flocculus are the last two segments of the folial chain of the hemisphere. Between lobules IX and $\mathrm{X}$ of the caudal vermis and the paraflocculus and flocculus the cortex is interrupted and white matter comes to the surface at the bottom of the paramedian sulcus and the interparafloccular sulcus in the center of the folial loop of the paraflocculus. The paraflocculus and flocculus thus constitute a curved, foliated band of cortex, which is delimited on its inner side by an extension of the white matter in the paramedian sulcus and on its outer border by the white matter of the cerebellar peduncles. The paraflocculus can be arbitrarily subdivided into dorsal and ventral limbs, which are known as the dorsal and the ventral paraflocculus (Stroud, 1895). In some species a part of the paraflocculus, known as the petrosal lobule, is lodged in the subarcuate fossa of the petrosal bone.

'The flocculus (Bolk's uncus terminalis) is a welldemarcated lobule located at the end of the folial chain of the hemisphere. Its border with the paraflocculus is formed by the posterolateral fissure, the earliest fissure to appear during ontogeny (Larsell, 1970). In the depth of the posterolateral fissure, the cortex of the flocculus and the paraflocculus are continuous. The gross anatomy of the paraflocculus and the flocculus of the rabbit was described by Brodal (1940) and their morphogenesis was traced by Larsell (1970). The most detailed account of the foliation of the rabbit flocculus stems from Yamamoto and Shimoyama (1977).

Some of the Purkinje cell zones projecting to the vestibular and cerebellar nuclei (Yamamoto and Shimoyama, 1977; Yamamoto, 1978; Bigaré, 1980; Voogd and Bigaré, 1980), and some of the climbing fiber zones (Yamamoto, 1979a), including the $\mathrm{C}_{2}$ zone, which receives climbing fibers from the rostral pole of the medial accessory olive (Gerrits and Voogd, 1982, 1989), extend across the posterolateral fissure into the ventral paraflocculus. This portion of the ventral paraflocculus with the same zonal structure as the flocculus is known as the medial extension of the ventral paraflocculus (ME, Gerrits and Voogd, 1982) in the cat and corresponds to folium $\mathrm{p}$ in the rabbit (Yamamoto and Shimoyama, 1977).

For this paper the white matter compartmentation of the rabbit flocculus was studied using Häggqvist's myelin stain and enzyme histochemistry for AChE. Visualizing the borders of compartments with $\mathrm{AChE}$ enzyme histochemistry is particularly straightforward and can be used to compare the zonal distribution of the Purkinje cells with the climbing and mossy afferents and to correlate electrophysiological and anatomical data (Robertson and Logan,

Abbreviations

$\begin{array}{ll}\text { ANS } & \text { ansiform lobule } \\ \text { ANT } & \text { anterior lobule } \\ \text { bc } & \text { brachium conjunctivum } \\ \text { bp } & \text { brachium pontis } \\ \mathrm{C}_{2} & \text { C }_{2} \text { zone and compartment } \\ \text { cc } & \text { cerebellar commissure } \\ \text { CO } & \text { cochlear nucleus } \\ \text { DLP } & \text { dorsolateral protuberance } \\ \text { dmcc } & \text { dorsomedial cell column } \\ \text { DV } & \text { descending vestibular nucleus } \\ \text { dY } & \text { dorsal group Y } \\ \text { F } & \text { fastigial nucleus } \\ \text { FC } & \text { floccular compartments 1-4 } \\ \text { fipl } & \text { posterolateral fissure } \\ \text { FLO } & \text { flocculus } \\ \text { fm, m } & \text { folium m of the floceulus } \\ \text { fp, } & \text { folium p of the ventral paraflocculus } \\ \text { f1 } & \text { folium } 1 \text { of the flocculus } \\ \text { f2 } & \text { folium } 2 \text { of the flocculus } \\ \text { f3 } & \text { folium } 3 \text { of the flocculus } \\ \text { f4 } & \text { folium } 4 \text { of the flocculus } \\ \text { G } & \text { granular layer } \\ \text { g } & \text { genu of the facial nerve } \\ \text { IA } & \text { anterior interposed nucleus } \\ \text { IP } & \text { posterior interposed nucleus } \\ \text { I. } & \text { lateral cerebellar nucleus } \\ \text { lö } & \text { Löwy's fiber bundle } \\ \text { Ipc } & \text { parvicellular part of the lateral cerebellar nucleus } \\ \end{array}$

$\begin{array}{ll}\text { LV } & \text { lateral vestibular nucleus } \\ \text { M } & \text { molecular layer } \\ \text { mlf } & \text { medial longitudinal fascicle } \\ \text { MV } & \text { medial vestibular nucleus } \\ \text { no } & \text { nucleo-olivary tract } \\ \text { P } & \text { Purkinje cell layer } \\ \text { pf } & \text { floccular peduncle } \\ \text { PFL } & \text { paraflocculus } \\ \text { PFLd } & \text { dorsal paraflocculus } \\ \text { PFIv } & \text { ventral paraflocculus } \\ \text { PMD } & \text { paramedian lobule } \\ \text { POST } & \text { posterior lobe } \\ \text { r } & \text { acetylcholinesterase-positive cell group r } \\ \text { rb } & \text { restiform body } \\ \text { rIV } & \text { lateral recess of the fourth ventricle } \\ \text { sad } & \text { dorsal acoustic stria } \\ \text { SI } & \text { simplex lobule } \\ \text { sipfl } & \text { intraparaflocelar sulcus } \\ \text { SV } & \text { superior vestibular nucleus } \\ \text { u } & \text { uncinate fascicle } \\ \text { vY } & \text { ventral group Y } \\ \text { V } & \text { trigeminal complex nerve } \\ \text { W } & \text { white matter } \\ \text { y } & \text { groupy } \\ \text { VI } & \text { abducens nucleus } \\ \text { VII } & \text { facial nerve } \\ \text { VIII } & \text { vestibulocochlear nerve } \\ \text { IX } & \text { lobule lX (uvulia } \\ & \end{array}$


1986; Tan et al., 1989, 1995a,b; Van der Steen et al., 1991, 1994; Simpson et al., 1992).

\section{MATERIALS AND METHODS}

Forty-five sectioned and $\mathrm{AChE}$-stained brains of pigmented Dutch belted rabbits were available. Some of these rabbits were also used for axonal tracing or electrophysiological experiments to be reported in subsequent papers. For AChE histochemistry the rabbits were deeply anesthetized with Nembutal and perfused intracardially first with 1 liter of saline at room temperature, then with 2 liters of a solution containing $1-3 \%$ paraformaldehyde and $0.5-1.25 \%$ glutaraldehyde in $0.1 \mathrm{M}$ phosphate buffer $(\mathrm{pH} 7.2-7.4)$ at room temperature, and finally with $10 \%$ sucrose in $0.1 \mathrm{M}$ phosphate buffer ( $\mathrm{pH} 7.2-7.4$ ) at $4^{\circ} \mathrm{C}$. The brainstem and cerebellum were removed, rinsed in $10 \%$ sucrose phosphate buffer, and embedded in a solution of $10 \%$ gelatin and $10 \%$ sucrose, which was hardened in $10 \%$ formalin. The embedded tissue was stored overnight in $30 \%$ sucrose phosphate buffer, after which it was cut into 30- or 40- $\mu \mathrm{m}$ transverse, horizontal or sagittal sections and processed for AChE. We used a standard thiocholine method to demonstrate AChE activity in the cerebellum (Geneser-Jensen and Blackstad, 1971). Acetylthiocholine acted as a substrate and ethopropazine as a blocking agent for nonspecific cholinesterases (Hess and Voogd, 1986). Incubation times of 6-9 hours were used to obtain optimal staining of the AChE-positive fibers of the raphes. The sections were developed in a solution of $10 \%$ ferricyanide for 10 minutes, then rinsed in water, coverslipped, and examined with a light microscope.

Alternate sections for the Häggqvist (1936) staining procedure were stored in $10 \%$ formaldehyde for several weeks. After mounting, the slides were immersed in a solution of $10 \%$ potassium bichromate and $1 \%$ calcium chloride at room temperature for 4-5 days, then rinsed in distilled water, and left in $96 \%$ alcohol for 1 day. Before staining in the Häggqvist solution (methylblue and eosin, 1-24 hours) the slides were immersed for 30 minutes in $10 \%$ phosphomolybdenic acid. A complete set of transversely sectioned Häggqvist-stained, celloidin-embedded $40-\mu \mathrm{m}$ sections through the rabbit cerebellum was also used (see Voogd and Feirabend, 1981 for details on the Häggqvist stain). Three-dimensional reconstructions of the flocculus and its white matter compartments were prepared from styrofoam sheets or with the aid of the MacReco program running on an Apple MacIntosh II computer.

The cerebellar nuclei of the rabbit were subdivided according to Weidenreich (1899), Ogawa (1935), and Ono and Kato (1938). The subdivision of the vestibular nuclei of the rabbit used in this paper was published by Epema et al. (1988). It is based on the descriptions of Deiters (1865), Fuse (1912), Lorente de Nó (1933), Van der Schueren (1914), Van Gehuchten (1904), and Voogd (1964) in man, cat, and rabbit. It differs from the purely cytoarchitectonic subdivision of the vestibular nuclei of Brodal and Pompeiano (1957, cat) in the designation of the large neurons of Deiters' nucleus, located within the juxtrarestiform body, as the lateral vestibular nucleus (LV). The more ventrally located large and medium-sized neurons that are located outside the juxtrarestiform body and that were included in the lateral vestibular nucleus of Brodal and Pompeiano (1957) are considered to belong to the medial vestibular nucleus (MV) and are indicated as its magnocellular part (MVmc).

\section{RESULTS Morphology of the flocculus and the paraflocculus}

The flocculus is applied to the lateral surface of the middle cerebellar peduncle. In sections incubated for $\mathrm{AChE}$, a narrow strip of intensely stained fibers marks the border between the white matter of the flocculus and the middle cerebellar peduncle (Figs. 1-4, 10-12). The flocculus consists of three or four rostrolaterally facing folia, which are numbered f1-4 from ventral to dorsal. A short stretch of cortex of $f 1$ that is folded back on the surface of the middle cerebellar peduncle (folium $m$ of Yamamoto and Shimoyama, 1977) serves as the attachment of the roof of the lateral recess. Folia f3 and f 4 are often fused, as is the case in the cerebellum depicted in Figure 1. Caudally f3 and $f 4$ taper and merge with folium $\mathrm{p} ; \mathrm{fm}, \mathrm{f} 1$, and $\mathrm{f2}$ fuse into a single folium. The posterolateral fissure demarcates the flocculus from the ventral paraflocculus. ${ }^{1}$ This fissure runs obliquely along the medial side of folium $\mathrm{f} 4$ to the caudomedial pole of the flocculus, where it opens on the ventral surface of the cerebellum. The folium of the ventral paraflocculus bordering on the flocculus ( $\mathrm{fp}$ or folium $\mathrm{p}$ of Yamamoto and Shimoyama, 1977) occupies a similar, oblique position. Rostrally the cortices of $f 4$ (or the fused folia f3 and f4) and folium $p$ are continuous across the posterolateral fissure (Fig. 2, arrows in nos. 5-12; Fig. 10C,D). More caudally, where the ventral paraflocculus starts to deviate laterally, white matter coming to the surface in the posterolateral fissure separates folium $\mathrm{p}$ from the caudal pole of the flocculus (Fig. 2, nos. 13-16). The cortex of the ventral paraflocculus (PFLv) covers the ventral surface of the parafloccular stalk and forms a rosette of three folia on the ventrocaudal aspect of the petrosal lobule. The two rosettes on the dorsal and caudomedial aspect of the petrosal lobule belong to the dorsal paraflocculus (PFLd; Fig. 1A,C; see also Fig. 7 ).

The folial chain of the paraflocculus and flocculus is reflected on the ventrolateral surface of the cerebellum. As a consequence, the mediolateral position of these lobules is reversed when compared with the proximal part of the chain, with their outer border facing medially. Caudally, the cortex of the paraflocculus is continuous with the paramedian lobule. More rostrally, white matter extending from the surface of the middle cerebellar peduncle separates the cortex of the paraflocculus and the flocculus from the anterior lobe and the simple, ansiform, and paramedian lobules. The white matter that borders the cortex of the flocculus and paraflocculus on the lateral side is an extension of the white matter at the bottom of the paramedian sulcus between the vermis and hemisphere. It extends from lobules IX and X of the caudal vermis, along the caudal border of the paramedian lobule, and over the petrosal lobule, where it radiates over the caudomedial surface of the folia of the flocculus and paraflocculus.

\footnotetext{
1A dorsal and a ventral paraflocculus have been distinguished in the cerebellum of the rabbit by several authors (Brodal, 1940; Larsell, 1970), but the precise border between the lobules was never indicated. It is proposed that this border is situated at the transition in the AChE chemoarchitecture of the molecular layer of the paraflocculus (see Fig. 7).
} 



Fig. 1. Drawing of a computer reconstruction of the rabbit's right flocculus and paraflocculus. Only the molecular layer was reconstructed. A: Rostrodorsolateral view. The flocculus, ventral paraflocenlus, and dorsal paraflocculus are indicated with different symbols. For the border between dorsal and ventral paraflocculus see text and Figure 7. B: The ventral paraflocculus, same view as in A. C: Cartoon of the cortex of the rabbit cerebellum, showing the continuity in the folial chain of the hemisphere and the designations of its different segments. Asterisks indicate area without cortex in the center of the ansiform lobule.

\section{AChE staining of the cerebellar cortex}

The granular layer of the rabbit cerebellar cortex stains more intensely for $\mathrm{AChE}$ than the molecular layer. The two layers are separated by the AChE-negative Purkinje cells. The staining in the granular layer is irregular with strongly reactive patches scattered among less reactive granule cells and neuropil. The AChE-positive patches were identified as glomeruli and Golgi cells, first by Gerebtzoff (1959) and later by many others (Csillik et al., 1963; Altman and Das, 1970; Brown and Palay, 1972). Generally the staining increases in the superficial part of the granular layer, next to and in between the Purkinje cells. Strong and more uniform AChE staining is present in the entire granular layer of the flocculus. The staining of the granular layer of folium $p$ and its transition into the flocculus is particularly dense (Fig. 12). The molecular layer of the flocculus and the PFLv can be subdivided into two layers. The lower onethird of the molecular layer next to the Purkinje cell layer is more densely stained than the superficial two-thirds. The AChE staining in the lower one-third disappears abruptly at the proposed border of the PFLv with the PFLd (Fig. 7A, solid arrow). The molecular layer of the PFLd is poor in AChE. Medium-sized AChE-positive cells are found scattered over the lower half of the molecular layer in all lobules of the rabbit cerebellum (Fig. 7B,C). According to Spaçek et al. (1973), these AChE-stained cells correspond to the displaced Golgi cells of Ramón y Cajal (1911).

\section{Compartments and raphes in the white matter of the flocculus and the paraflocculus}

$\mathrm{AChE}$ histochemistry reveals narrow strips of densely stained fibers in the white matter of the cerebellum (Figs. 2-4). The strips separate more lightly stained fiber compartments. In serial sections the AChE-positive strips can be traced as sheets throughout the white matter of the flocculus and the paraflocculus. In a drawing of a computer reconstruction of the white matter of the flocculus the compartments appear as oblique slabs that taper toward the caudal pole of the flocculus (Fig. 6). In the white matter of the flocculus four raphes can be distinguished. They subdivide the white matter into five compartments (Figs. 2-4,6). The most lateral compartment, which can be traced into the white matter of the paraflocculus, corresponds to the $\mathrm{C}_{2}$ compartment of Voogd $(1964,1969)$. The other four are numbered from lateral to medial and termed $\mathrm{FC}$ (floccular compartment) 1-4. The raphes are named after the compartments they border. Compartments $\mathrm{FC}_{1}, \mathrm{FC}_{2}$, and $\mathrm{FC}_{3}$ are present in all folia of the flocculus and in folium p. $\mathrm{FC}_{2-4}$ are present in the rostralmost sections of the transverse series depicted in Figure 2, $\mathrm{FC}_{1}$ appears somewhat more caudally, and $\mathrm{C}_{2}$ is present only in the caudal half of the flocculus. When traced caudally the compartments shift medially and ventrally (Fig. 6).

The AChE-positive fibers located at the borders of the compartments correspond to accumulations of dark blue, small-diameter myelinated fibers in Häggqvist-stained sections. These accumulations of small fibers were called raphes by Voogd (1964). They separate bundles of larger diameter fibers, which occupy the interior of the compartments (Fig. 5). At the sites where the raphes meet the granular layer, this layer often stains more intensely. At these points the granular layer also shows a characteristic bulging into the white matter. These bulges form strictures in the white matter. In the vermis and hemispheres, concentrations of AChE-positive glomeruli are obvious in the midline and at certain parasagittal positions. Such a regular glomerular staining pattern is not seen in the flocculus or the paraflocculus.

Raphe $\mathrm{C}_{2} / 1$, the most lateral and one of the most intensely AChE-staining raphes, can be traced from the white matter of the paraflocculus into the flocculus. It delimits a white matter compartment located on the caudal side of the stalk of the paraflocculus. Horizontal and sagittal sections (Figs. 10A,B, 12, 13, 14C) reveal how this raphe becomes applied to the caudal border of the lateral cerebellar nucleus and continues as the border between the posterior interposed and lateral nuclei. The caudal compartment of the paraflocculus, which contains the posterior interposed nucleus can, therefore, be identified as the $\mathrm{C}_{2}$ 

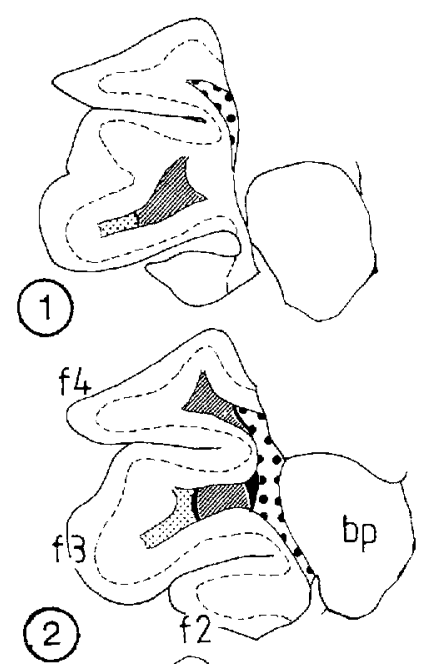

(3)
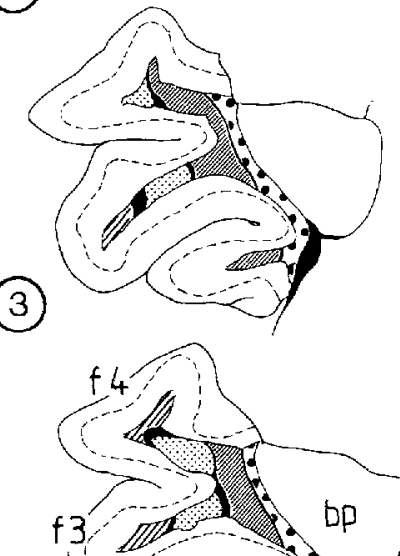

(4)

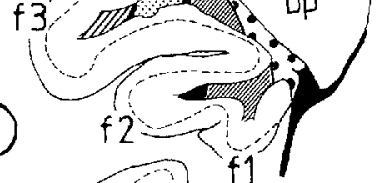

(5)

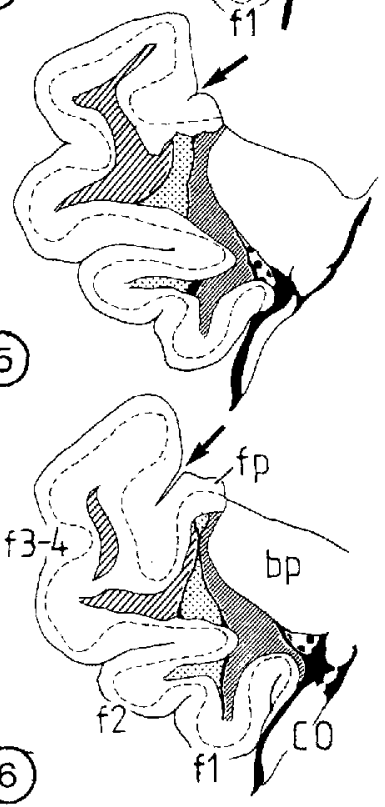

(7)


(8)



(9)
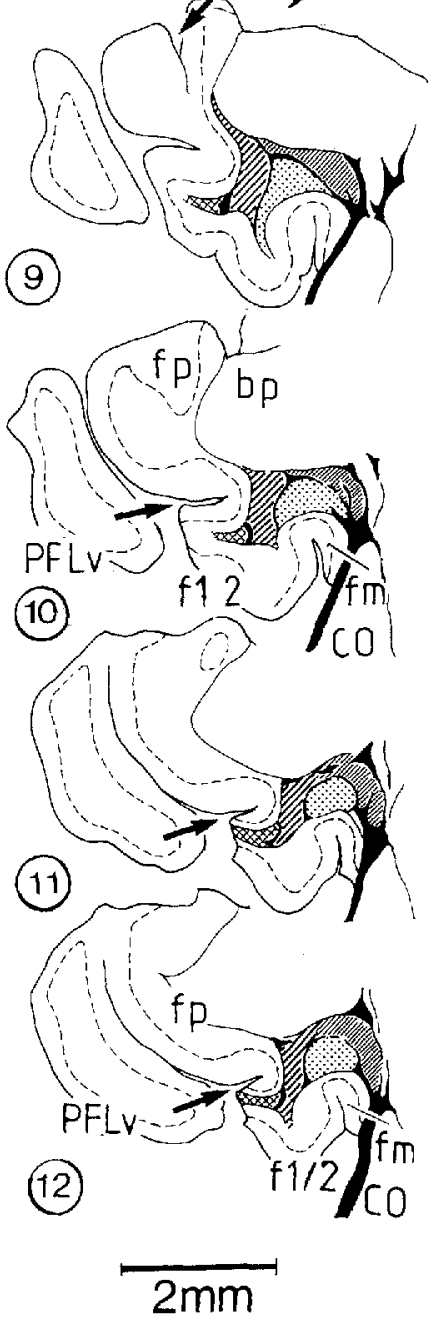

(13)



(14)
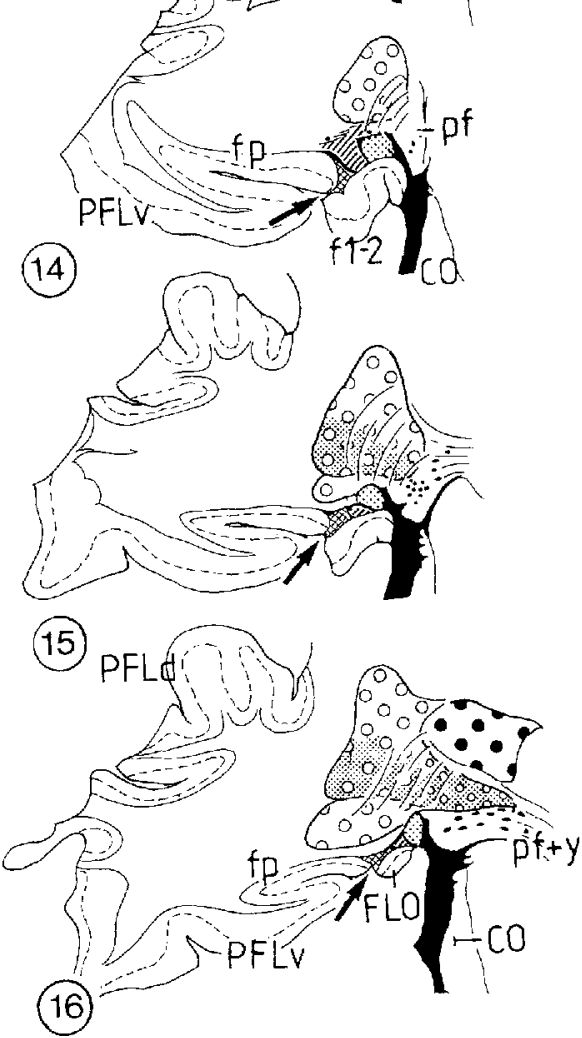

$C_{2}$ compartinent

FC1 compartment

FC2 compart ment

FC3 compartment

F[4 compartment

Lateral nucleus: ACHE-rich

Lateral nucleus: ACHE-poor

parvicellular lateral nud.

:- anterior interposed nucl.

ACHE
Fig. 2. Schematic drawing of 16 equally spaced transverse sections through the flocculus and ventral paraflocculus showing the location and course of acetylcholinesterase (AChE)-positive raphes. Section 1 is situated most rostrally, and section 16 is the most caudal one. The white matter compartments $\left(\mathrm{C}_{2}, \mathrm{FC}_{1}-\mathrm{FC}_{4}\right)$ and cerebellar nuclei are indicated with different symbols. Arrow points to the posterolateral fissure. Between the caudal pole of the flocculus and folium $p$ the cortex is interrupted. 




Fig. 3. A,B: Photomicrographs of two AChE-stained transverse sections through the left flocculus corresponding to sections 3 and 6 of Figure 2. Small white arrows indicate AChE-positive raphes between the compartments. 

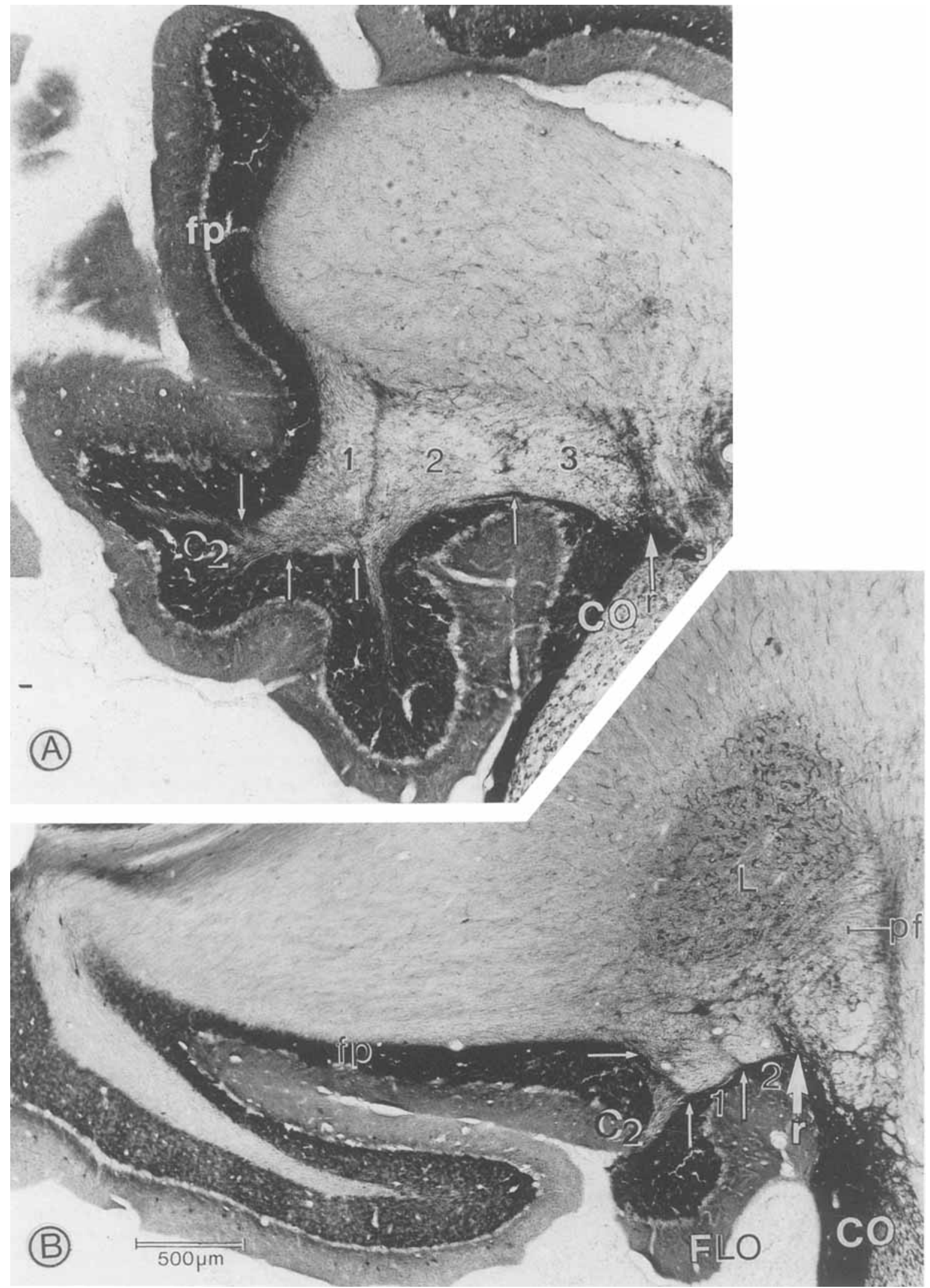

Fig. 4. A,B: Photographs of two AChE-stained transverse sections through the flocculus corresponding to a section midway between sections 8 and 9 of Figure 2 and to section 14 of Figure 2. Small white arrows indieate $\mathrm{AChE}$-positive raphes between compartments. Large white arrows indicate cellular, AChE-positive ridge (r). Same magnification as Figure 3. 

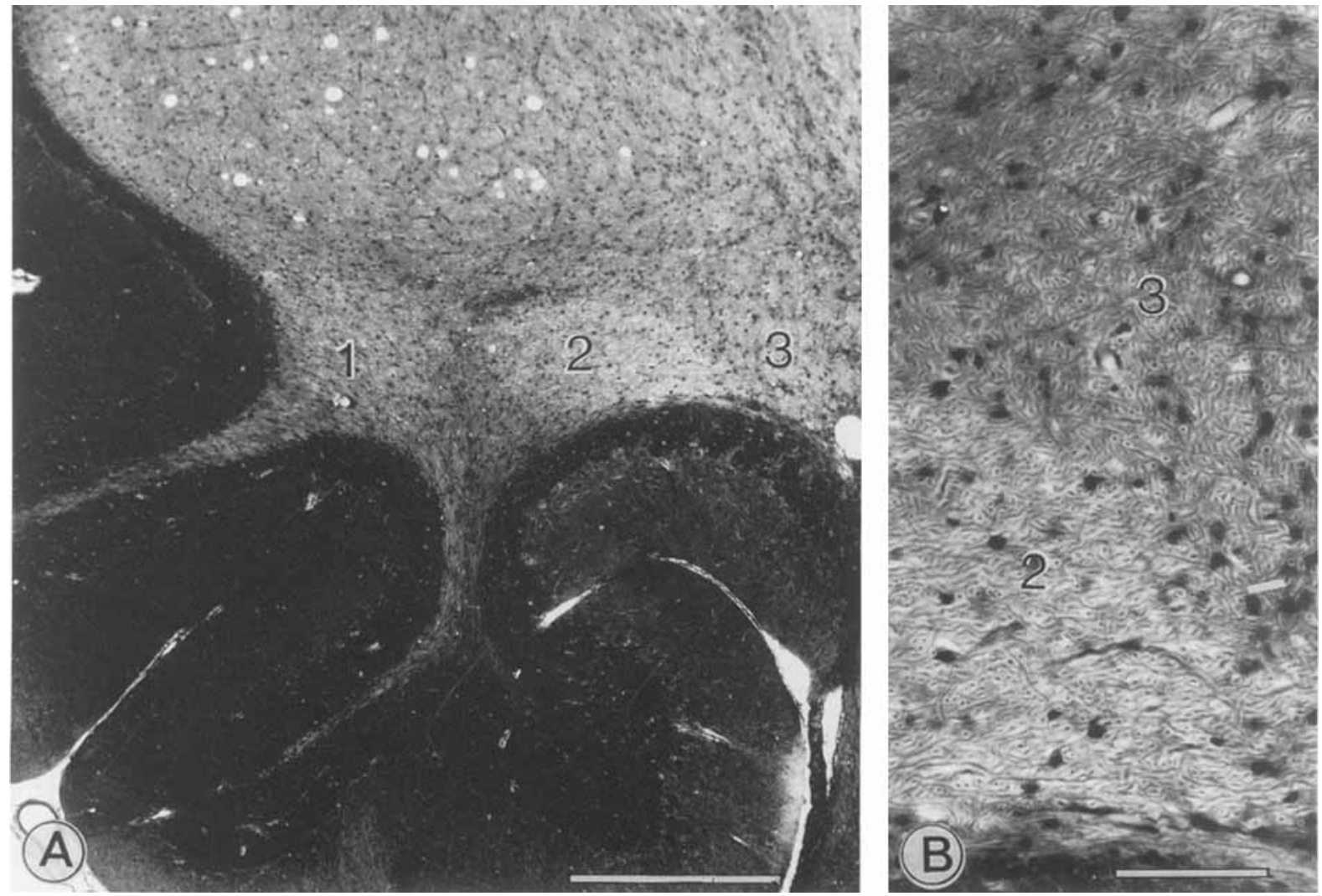

Fig. 5. Photographs of a Häggqvist-stained transverse section through the flocculus (A) and a high power view of the border area between compartments $\mathrm{FC}_{2}$ and $\mathrm{FC}_{3}(\mathbf{B})$. The level of the section corresponds approximately to Figure $4 \mathrm{~A} .1-3$, compartments $\mathrm{FC}_{1-3}$. Note the relatively coarse fibers in $\mathrm{FC}_{2}$. Scale bars $=500 \mu \mathrm{m}$ in $\mathrm{A}, 75$ $\mu \mathrm{m}$ in $\mathrm{B}$. compartment. The $\mathrm{C}_{2}$ compartment continues from the ventral most folium of the ventral paraflocculus (folium p) into the lateral white matter of the flocculus (Figs. 2, 4, 6, 8, 10-14). The large rostral compartment of the paraflocculus corresponds to the $\mathrm{D}$ compartment, but it does not show clear signs of a subdivision into $\mathrm{D}_{1}$ and $\mathrm{D}_{2}$ compartments, as in the cat, ferret, and monkey (Voogd, 1964, 1969, Voogd et al., 1987; see, however, asterisk in Fig. 12A). Compartment $\mathrm{C}_{2}$ stains rather densely for $\mathrm{ACh}$.

Raphe $1 / 2$ is distinct and is located between $\mathrm{FC}_{1}$ and $\mathrm{FC}_{2}$. $\mathrm{FC}_{2}$ is characterized by its pale appearance in comparison with the adjoining compartments (Figs. 4A, 11). Häggqviststained sections give the impression that the fibers contained in $\mathrm{FC}_{2}$ have a slightly larger caliber than those in the adjoining compartments (Fig. 5B). The number of larger fibers decreases and the amount of AChE increases in the lateral half of $\mathrm{FC}_{2}$, toward the intensely stained raphe $1 / 2$ (Figs. 4A, 5A). Raphes $1 / 2$ and $2 / 3$ fuse in the caudal half of the white matter of the flocculus and folium $\mathrm{p}$, dorsal to $\mathrm{FC}_{2}$, which now has the shape of a triangle, with its base resting on the granular layer of folium f1 and its apex pointing dorsally. The point of fusion of the two raphes around the apex of $\mathrm{FC}_{2}$ can always be recognized by intense staining for AChE (Figs, 4A, 11A, star). The fused raphe $1 / 3$ extends dorsally as the border between $\mathrm{FC}_{1}$ and $\mathrm{FC}_{3}$ and terminates at the granular layer of folium p. (Fig. 2, nos. 7 and 8).

Compartment $\mathrm{FC}_{3}$ is located between raphe $2 / 3$ for the fused raphe $1 / 3$ ) laterally and raphe $3 / 4$ or, more caudally where $\mathrm{FC}_{4}$ has disappeared, the middle cerebellar peduncle medially. Raphe $2 / 3$ stains less intensely for AChE than the other raphes but can be identified because it separates the dense staining in $\mathrm{FC}_{3}$ from the pale area of $\mathrm{FC}_{2}$. Compartment $\mathrm{FC}_{4}$ is narrow and located parallel to the border of the flocculus with the middle cerebellar peduncle. $\mathrm{FC}_{4}$ can be distinguished as a separate compartment only in the rostral one-third of the flocculus (Fig. 2, nos. 1-6; 3A, 14B). Raphe $3 / 4$ fuses with the medial border of the flocculus, and the fibers of $\mathrm{FC}_{4}$ disappear into a meshwork of $\mathrm{AChE}$-positive cells located between the cochlear nuclei, the middle cerebellar peduncle, and the restiform body (Fig. 2 , no. $7 ; 4 \mathrm{~A}, \mathrm{~B}$ ).

Compartment $\mathrm{FC}_{1}$ straddles the posterolateral fissure over most of its extent and continues for some distance into the white matter of folium $p$ (Fig. 2, nos. 5-13). With regard to folium $\mathrm{p}, \mathrm{FC}_{2}$ is represented only in its rostral pole (Fig. 2 , nos. 5 and 6 ). $\mathrm{FC}_{3}$ is narrow in the rostral white matter of folium $p$ and widens more caudally (Fig. 2, nos. 5-8). Its caudal extent and its relation with the $\mathrm{D}$ compartment of the paraflocculus could not be determined. $\mathrm{FC}_{4}$ has no representation in folium $p$.

An additional raphe, which subdivides compartment $\mathrm{FC}_{1}$, is sometimes present in an intermediate position between the intensely stained raphe $\mathrm{C}_{2} / 1$ and raphe $1 / 2$, which itself can be recognized by its fusion with raphe $2 / 3$. This additional raphe is present in the horizontally sectioned specimen of Figures 10 (arrow) and $11 \mathrm{C}$ (open arrow), but it cannot be recognized in the transverse sections of the case illustrated in Figure 2. 

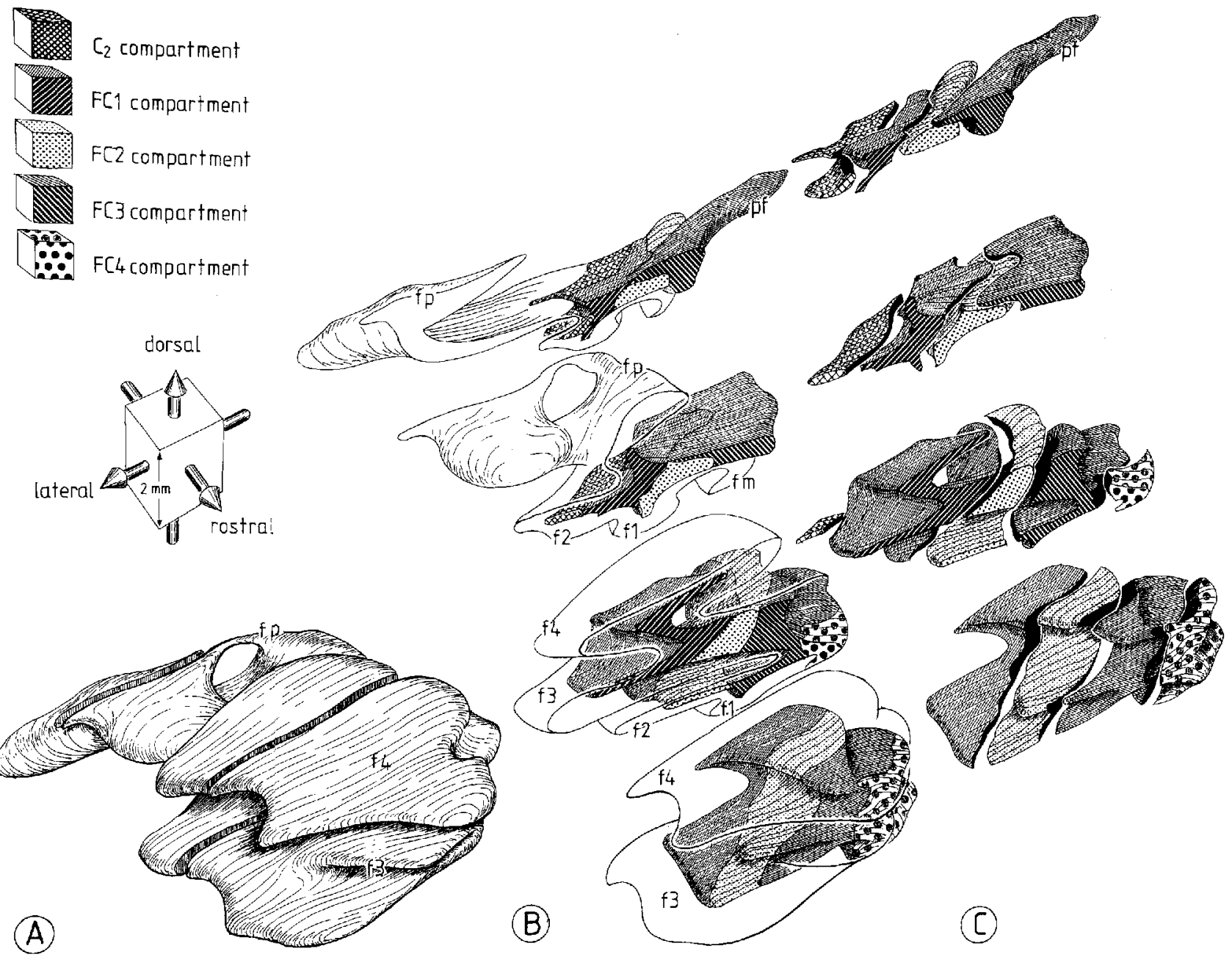



Fig. 6. Drawing of a dorsorostrolateral view of a computer reconstruction of the floceulus (A), the cortex and the five white matter compartments $(\mathbf{B})$, and the white matter compartments pulled slightly apart (C). Note oblique orientation of the compartments. In the cauda

\section{Floccular peduncle and topographical relations with group $y$ and the cerebellar nuclei}

Caudally, where the middle cerebellar peduncle has entered the cerebellum, fibers of $\mathrm{FC}_{1-3}$ enter the ventral region of the lateral cerebellar nucleus and/or shift medially to constitute the incipient floccular peduncle in the area ventromedial to the lateral cerebellar nucleus, dorsal to the cochlear nucleus, and medial to the restiform body. In this process raphe $1 / 3$, dorsal to $\mathrm{FC}_{2}$, becomes less distinct (Fig. 2, nos. 11 and 12). Much reduced compartments $\mathrm{FC}_{1}$ and $\mathrm{FC}_{2}$, flanked by the $\mathrm{C}_{2}$ compartment, which does not participate in the formation of the floccular peduncle, can be traced through the caudal pole of the flocculus, into the roof of the lateral recess (Figs. 4B, 14B). Cells and neuropil of group $y$ appear in the area of the floccular peduncle, and the entire complex of the peduncle and group y arches medially over the restiform body ventral to the lateral cerebellar nucleus to merge with the vestibular nuclei (Fig. 8C,D).

Group y can be considered as the bed nucleus of the floccular peduncle. Ventral and dorsal subdivisions of group flocculus compartment $\mathrm{FC}_{4}$ is not present, and $\mathrm{FC}_{1}$ and $\mathrm{FC}_{3}$ overlie the $\mathrm{FC}_{2}$ compartment. The reconstruction was generated from sections depicted in part in Figure 2.

y can be distinguished (Fig. 9). The small cells of the ventral subdivision constitute a dense, AChE-positive cap over the restiform body at its border with the floccular peduncle. The dorsal division contains $\mathrm{AChE}$-positive neurons located either in strands or individually between the fibers of the floccular peduncle, ventral to the parvicellular extension of the lateral cerebellar nucleus. The neurons of dorsal group $y$ are larger than those of ventral group $y$. The border between dorsal group $y$ and the parvicellular extension of the lateral cerebellar nucleus is not sharp, and at the interface of the two nuclei large cells of group y and small cells of the parvicellular extension intermingle. Medially, the floccular peduncle and the cells of group y merge with the rostral pole of the superior vestibular nucleus (Fig. 10B).

The relations and the composition of the floccular peduncle are most distinct in horizontal and sagittal sections. Laterally, the peduncle is separated from the $\mathrm{FC}_{2}$ compartment in the caudal pole of the flocculus by a ridge consisting of small, AChE-positive cells ( $r$ in Figs. 9, 10B, 13D). This ridge still separates the peduncle from a narrow offshoot of $\mathrm{FC}_{2}$ located in the wall of the lateral recess and penetrating 



Fig. 7. Photograph of an AChE-stained transverse section through the dorsal and ventral paraflocculus $(\mathbf{A})$ and high power views of the cortical layers of the dorsal (B) and the ventral parafiocculus (C). Note the abrupt change in staining density of the inner third of the molecular

layer of the dorsal paraflocculus at its proposed border with the ventral paraflocculus (large arrow in A). Note also the displaced Golgi cells in the molecular layer (triangles in B and C). Small white arrows in A indicate the raphe bordering the $\mathrm{C}_{2}$ compartment.

between group $\mathrm{y}$ and the dorsal cochlear nucleus (Figs. $13 \mathrm{E}, \mathrm{F}, 14 \mathrm{C}, \mathrm{D})$. Before the peduncle enters the caudal pole of the superior vestibular nucleus, it divides into rostral and caudal bundles. The caudal bundle stains more intensely for AChE and corresponds to Löwy's (1928) bundle (Figs. $10 \mathrm{~B}, 13 \mathrm{E}, \mathrm{F}, 14 \mathrm{D})$. This bundle passes medially in front of the cochlear nuclei. Near the lateral angle of the fourth ventricle, where it is located dorsal to the medial vestibular nucleus, it turns rostrally. The rostral bundle of the floccular peduncle becomes lost in the superior vestibular nucleus.

The subdivision of the cerebellar nuclear complex in the rabbit can best be appreciated in horizontal and sagittal AChE-stained sections. The lateral cerebellar nucleus is fairly compact, with a lateral tail extending into the stalk of the paraflocculus and a medially directed hilus. This nucleus consists of two groups of large neurons in an AChE-poor neuropil in the rostromedial and caudolateral parts of the nucleus, separated by an area with somewhat smaller cells in a strongly AChE-reactive neuropil (Figs. 8, 10, 13). Like most neurons of the cerebellar nuclei, they contain AChE. The caudolateral group of large cells constitutes the lateral tail and the caudal pole of the lateral nucleus. Medially, the lateral nucleus borders on the anterior interposed nucleus. Fibers from the white matter of the flocculus enter the ventral aspect of the lateral nucleus and traverse its AChE-rich border zone (Figs. 2, nos. 13-16; 8B,C). These fibers separate the ventromedial extension of the lateral nucleus, which contains small and medium-sized neurons in a moderately $\mathrm{AChE}$-reactive neuropil, from the lateral and caudal magnocellular shell of the lateral nucleus. This subnucleus is indicated as the parvicellular part of the lateral nucleus (Lpc, Fig. 9A). The floccular peduncle abuts the Lpc on its ventral and rostral side. A conspicuous AChE-positive patch of small round cells is located along the caudal and dorsal border of the Lpc ( $r$ in Figs. 9A, 10D, 


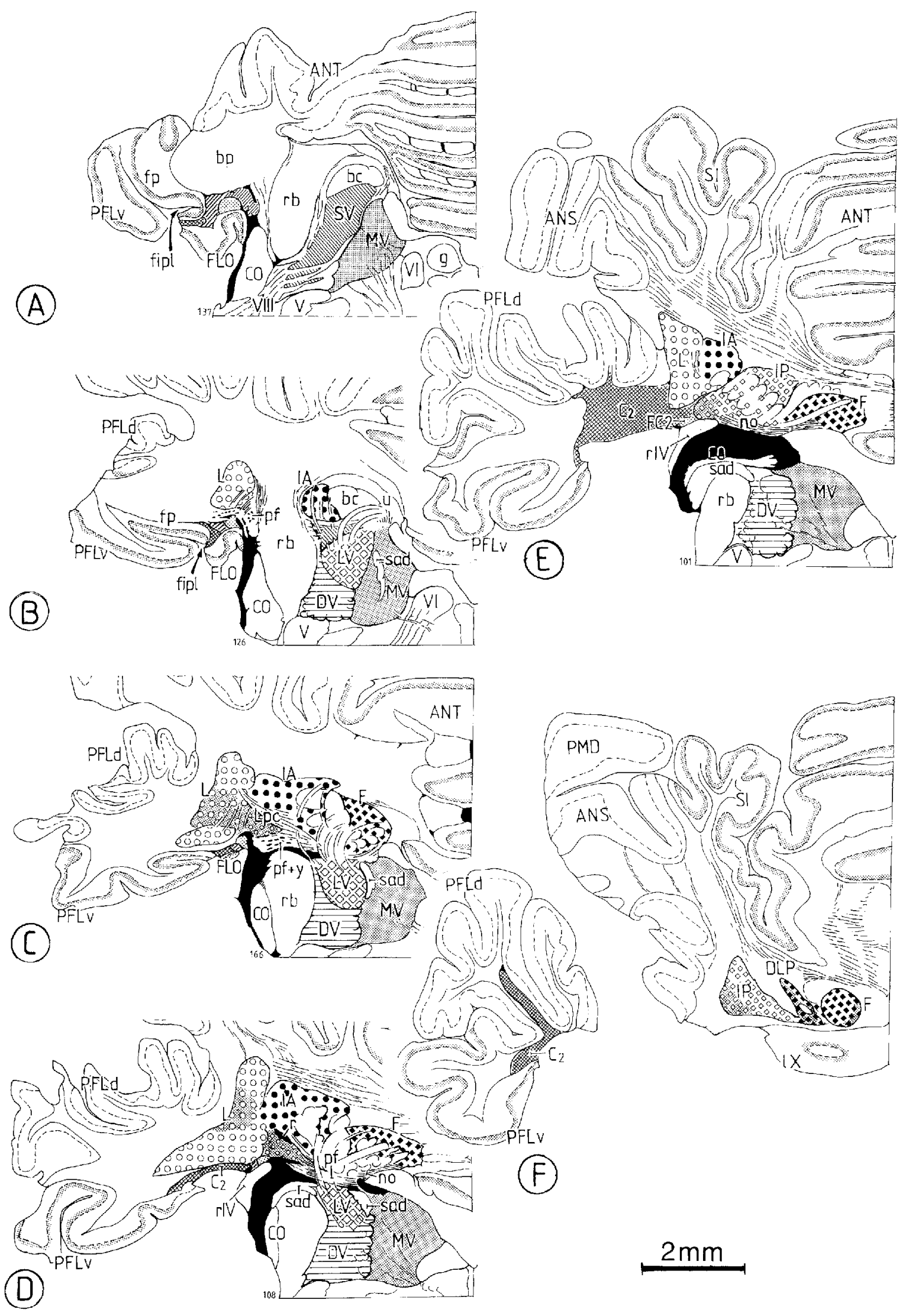

Fig. 8. A-F: Drawing of AChE-stained transverse sections through half of the cerebellum showing the close relationship between the flocculus, the floccular peduncle, group $y$, and the cerebellar and vestibular nuclei. Note the extent of compartment $C_{2}$. Sections $A$ and $F$

are, respectively, the most rostral and caudal ones of the series. For explanation of symbols used to indicate floccular compartments and cerebellar muclei, see Figure 13. The distribution of AChE in deep parts of the molecular layer is indicated by stippling. 

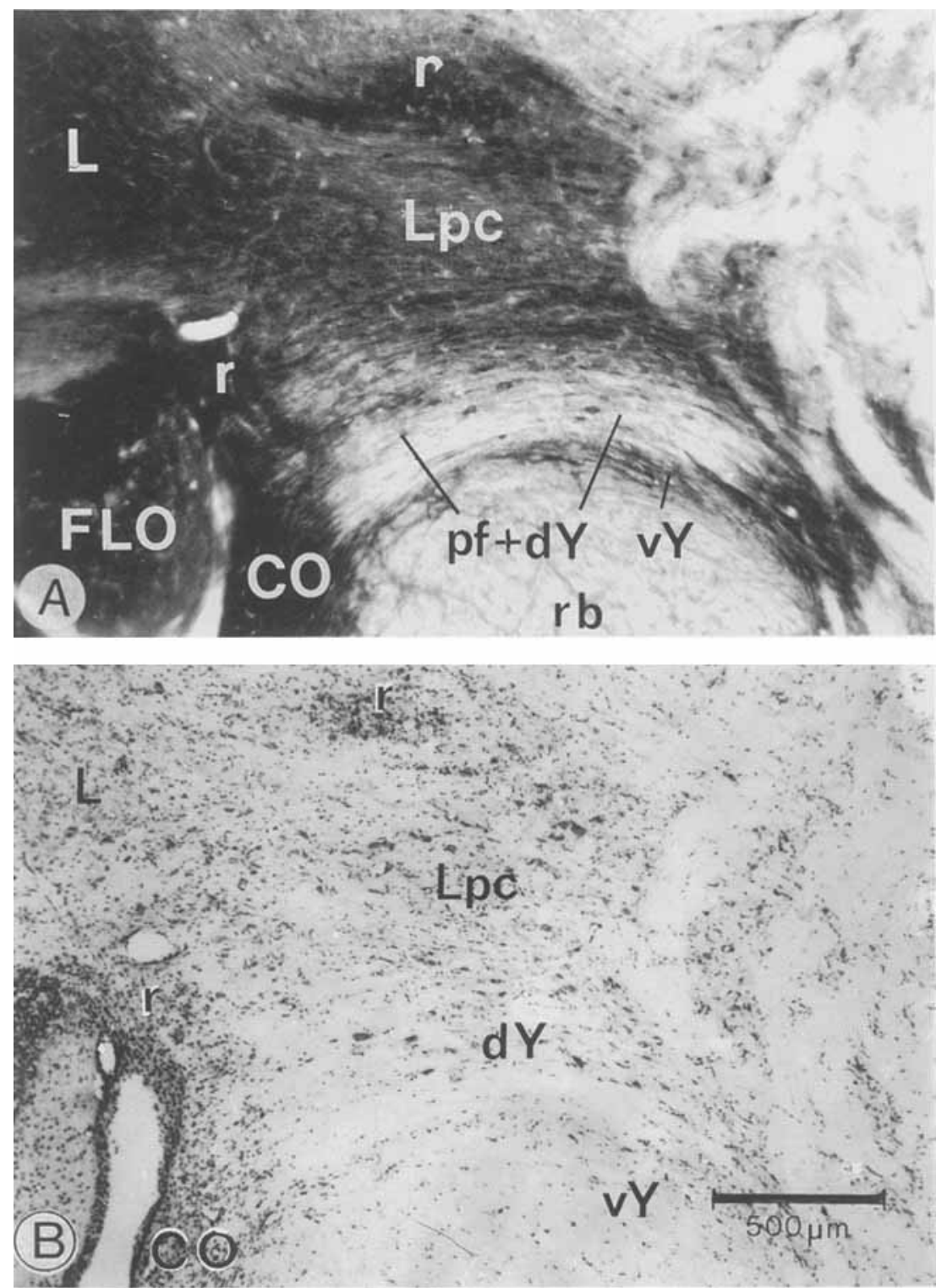

Fig. 9. Photographs of adjacent transverse AChE- (A) and Nisslstained $(\mathbf{B})$ sections through group y and the floccular peduncle. Small densely $\mathrm{AChE}$-stained cells are found between the white matter of the flocculus and the floccular peduncle and also dorsal to the parvicellular lateral nucleus. Ventral group y consists of small cells (mean, $24 \times 6$

$13 \mathrm{E}, 14 \mathrm{C})$. This cell group may be continuous with the AChE-positive cellular ridge separating the floccular peduncle from the flocculus. Medially, the Lpc joins the vestibular nuclei. Ventrally, it merges with the fibers of the floccular peduncle and dorsal group y.

The anterior interposed nucleus is located on the medial side of the lateral nucleus. It can be distinguished from the latter by its medium-sized neurons in a pale, non-AChEreactive neuropil. Lateral to the superior cerebellar peduncle, it extends far ventrally, bordering on the highly AChE-reactive superior vestibular nucleus (Figs. 8B, 10B). The posterior interposed nucleus is found in a rather medial and caudal position. Its ventrolateral pole reacts strongly for AChE and is sharply delimited by a fiber lamella from the lateral nucleus (Figs. 8E, 10A, 13E, 14C). $\mu \mathrm{m})$ in a densely AChE-stained matrix; the cells of dorsal group y are larger (mean, $32 \times 12 \mu \mathrm{m}$ ) and are located among the fibers of the floccular peduncle. Lpc contains small neurons (mean, $12 \times 12 \mu \mathrm{m}$ ), and the lateral cerebellar nucleus contains large cells (mean, $26 \times 22$ $\mu \mathrm{m})$.

The dorsal part of the nucleus contains large cells in a pale neuropil. A meshwork of cells separates the posterior interposed nucleus from the medial cerebellar nucleus. This meshwork is traversed by the efferent fibers of the posterior interposed nucleus, which continue as the medial one-third of the brachium conjunctivum, and by bundles of corticovestibular (perforating) fibers.

\section{DISCUSSION Distribution of AChE in the cerebellar cortex}

$\mathrm{AChE}$ is present in neuronal as well as nonneuronal tissues (Silver, 1974). In the brain, AChE is associated with the hydrolysis of acetylcholine in the synaptic cleft of 

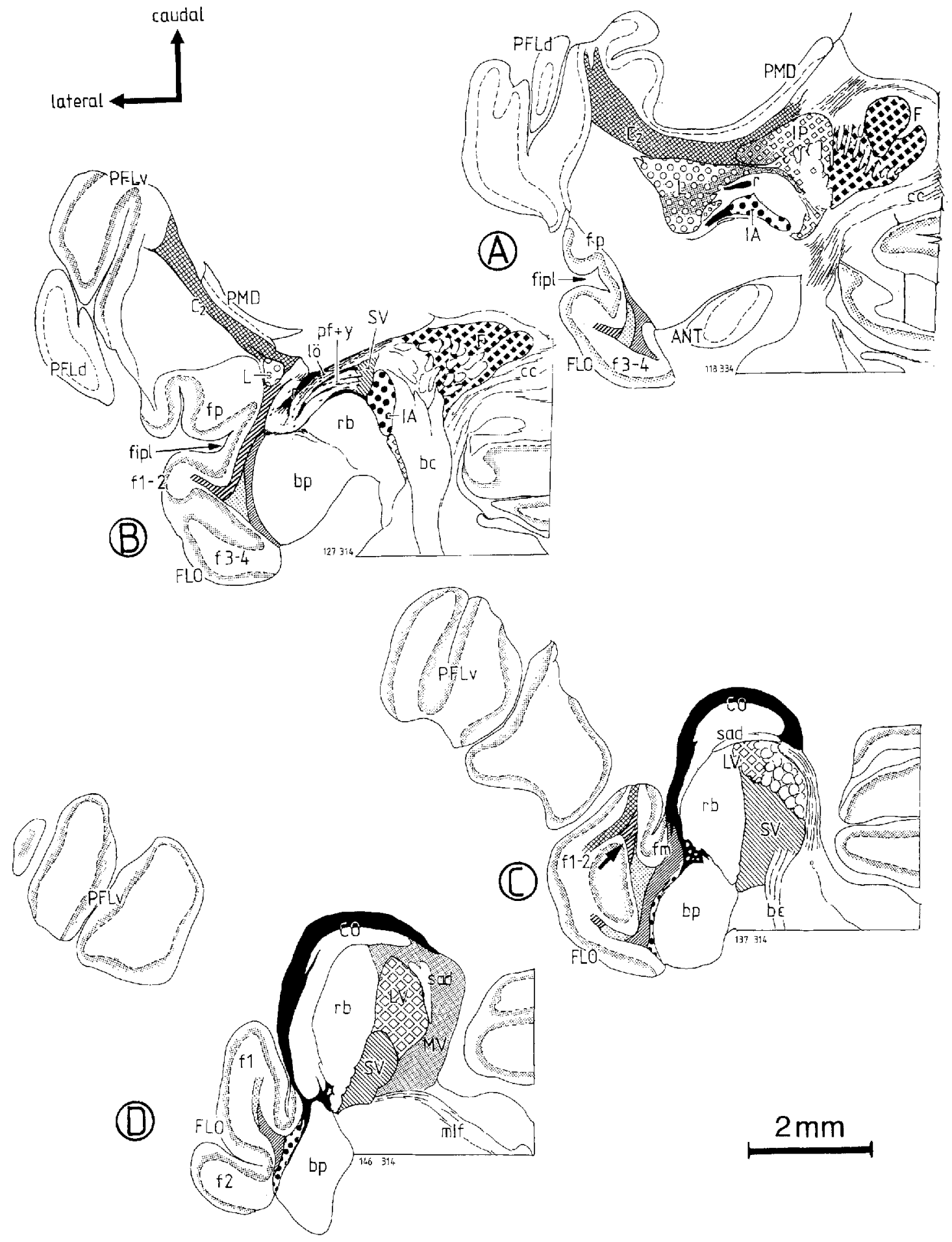

Fig. 10. A-D: Drawings of AChE-stained horizontal sections through the flocculus. A is the most dorsal and $\mathrm{D}$ the most ventral section. Compartment $\mathrm{FC}_{1}$ is subdivided by an additional raphe into medial and lateral parts (arrow in C). For explanation of symbols indicating compartments and cerebellar nuclei see Figure 1.3.

axonal terminals of cholinergic neurons and "cholinoceptive" cells. Other possible functions of $\mathrm{AChE}$ in the brain have been discussed by Greenfield (1984) and Appleyard and Jahnsen (1992). Pseudocholinesterase, which converts other substrates (Marani, 1982), is present in endothelial and glial cells (Barth and Ghandour, 1983), but was inhibited in our experiments by ethopropazine. Pseudocholinesterase was demonstrated in certain Purkinje cells in lobules IX and X of the cerebellum of the rat, but the flocculus was not investigated (Gorenstein et al., 1987). 

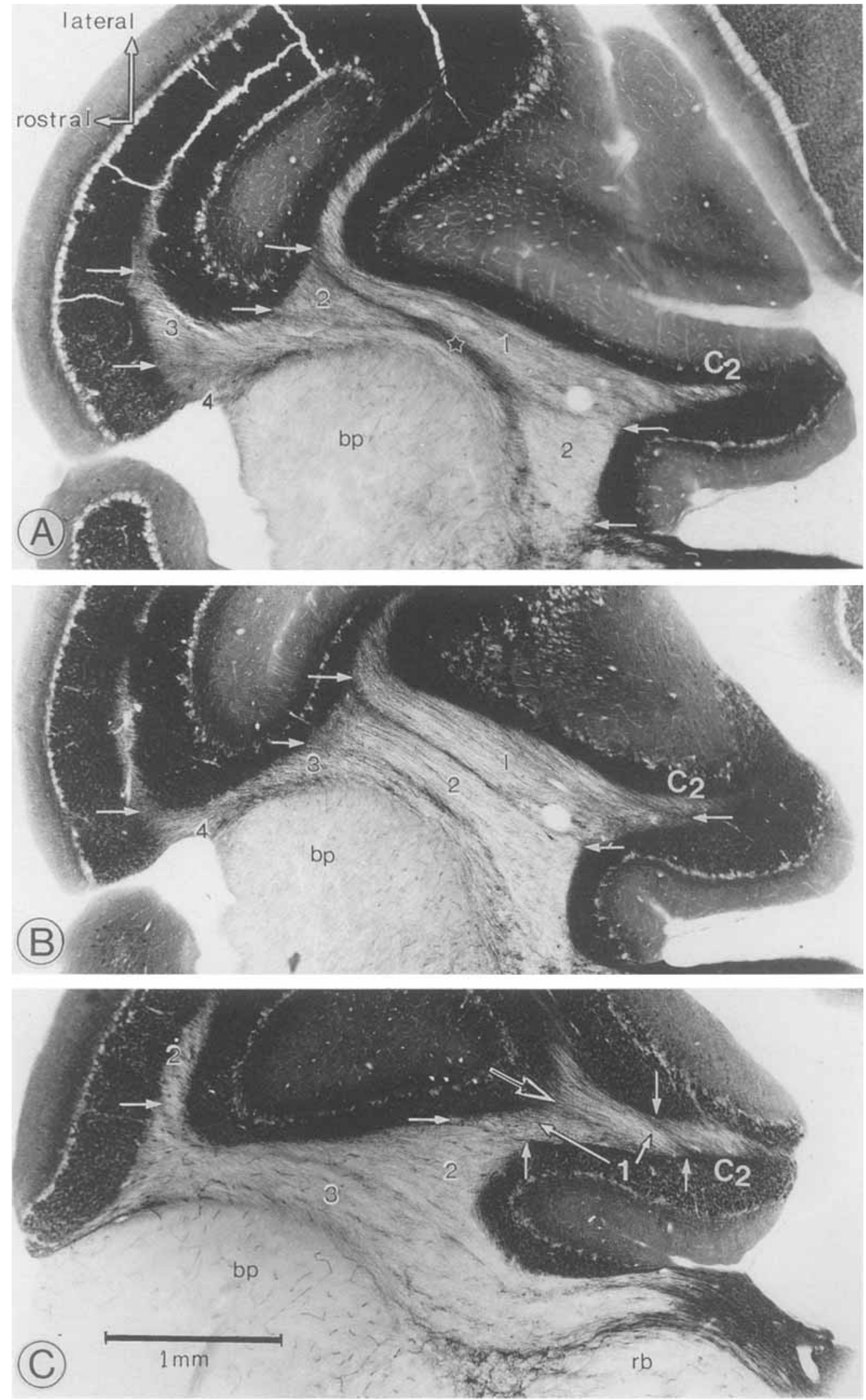

Fig. 11. A-C: Photographs of three horizontal sections through the flocculus. In the dorsalmost section (A) compartment $\mathrm{FC}_{2}$ has disappeared from the middle part of the floceulus and the $1 / 2$ and $2 / 3$ raphes have fused (fused raphe $1 / 3$ indicated with a star). Note the presence of an additional raphe (large arrow in $\mathrm{C}$ ), which subdivides $\mathrm{FC}_{1}$ into lateral and medial halves. Small arrows indicate the AChE-positive raphes between the compartments. Compartments $\mathbf{F C}_{1-3}$ are indicated with arabic numerals. Compare with Figure 10. 

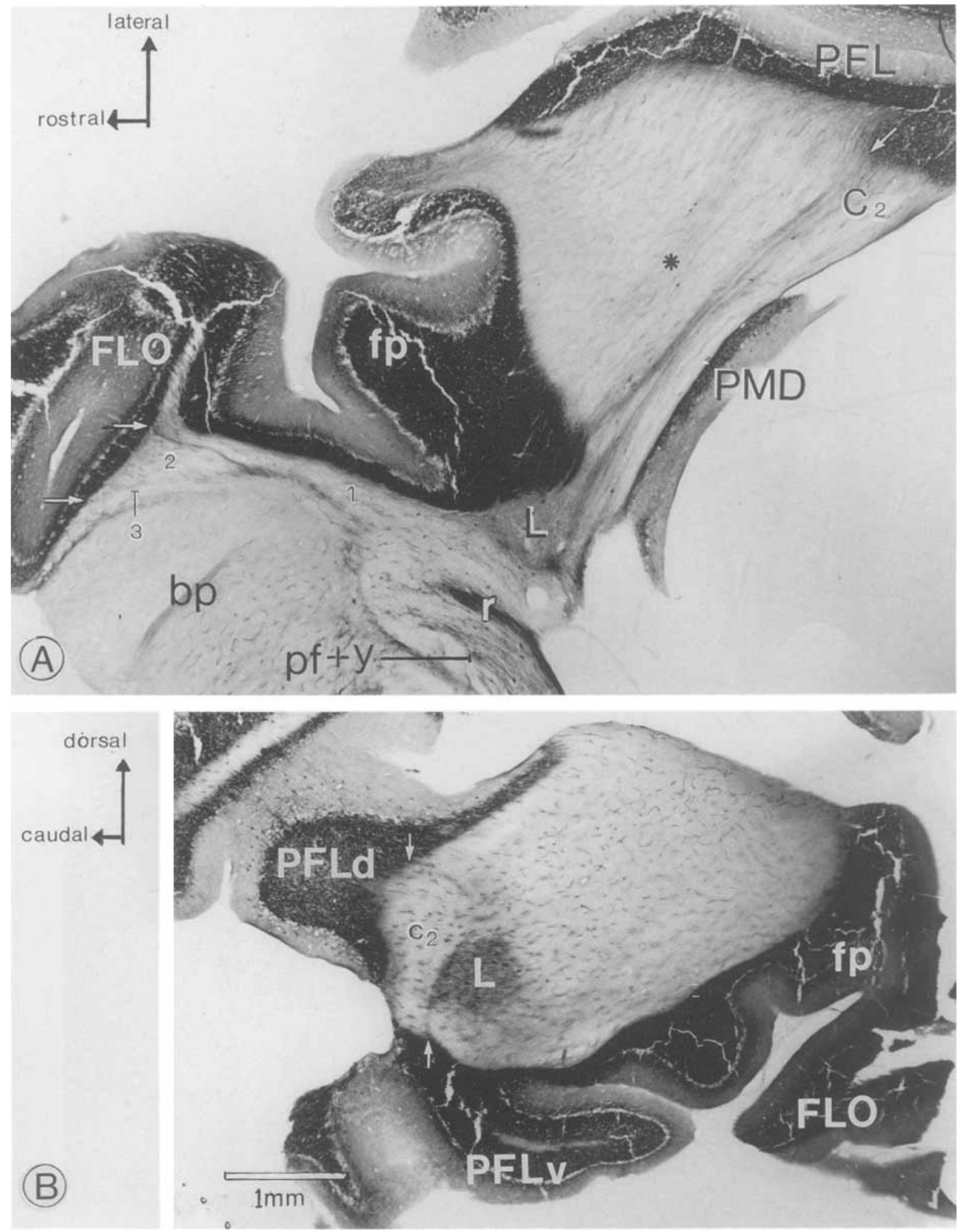

Fig. 12. Photographs of a horizontal (A) and a sagittal (B) section through the flocculus and paraflocculus. Note the caudal position of the $\mathrm{C}_{2}$ compartment in the parafloccular stalk. A densely AChE-positive cellular ridge separates the caudal white matter of the flocculus from the floccular peduncle in A. Asterisk in A indicates a vague raphe subdividing compartment $D$. Small white arrows in $A$ and $B$ indicate the AChE-positive raphes separating the compartments. Scale bar in B also applies to $\mathrm{A}$. 


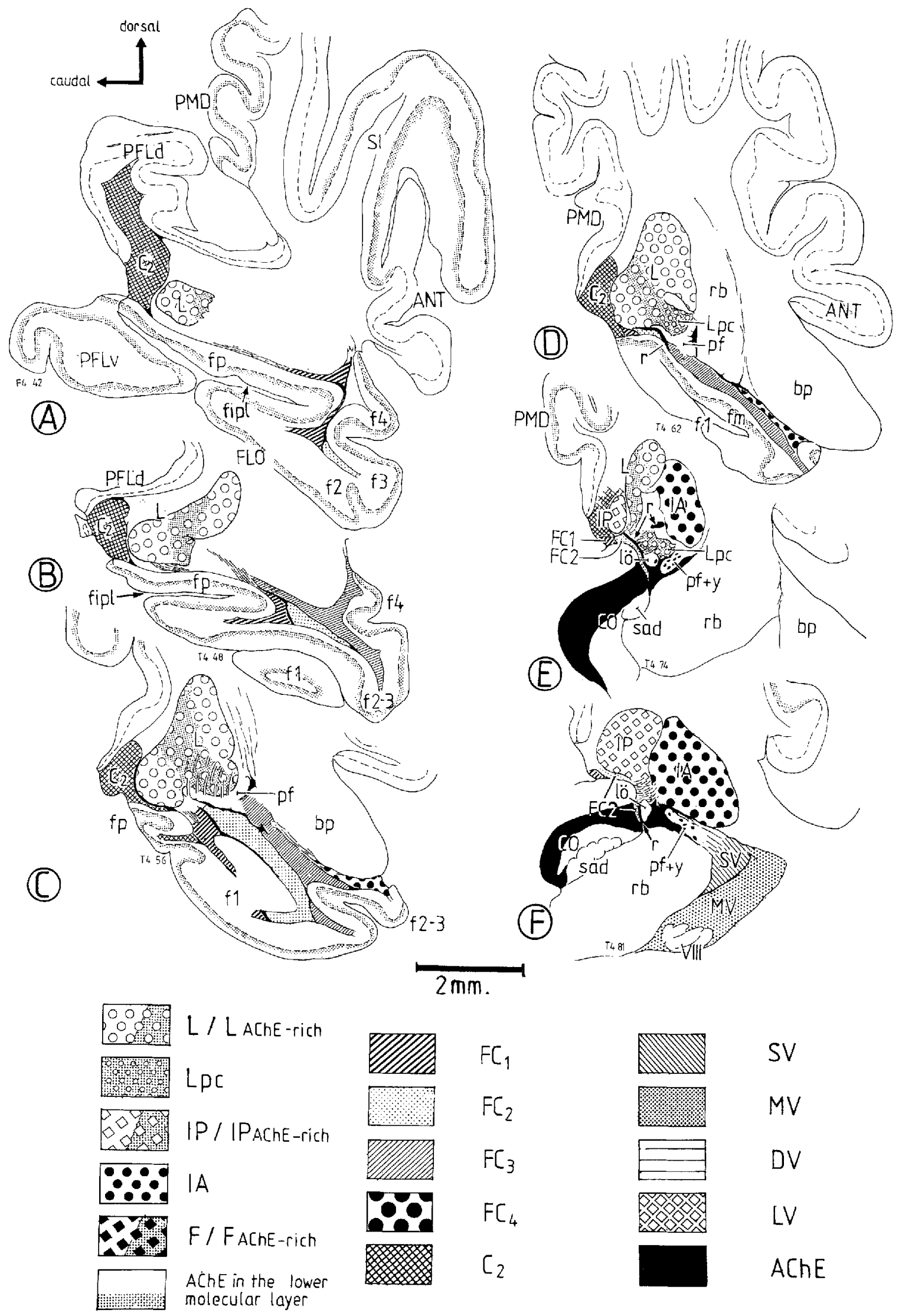

Fig. 13. A-F: Drawings of AChE-stained sagittal sections through the flocculus showing compartments in the flocculus, the parafloccular stalk, and the emerging floccular peduncle. Compare with Figures $12 \mathrm{~B}$ andl 14. 




Fig. 14. Photographs of sagittal sections through the flocculus. A. Lateral section through folium $\mathrm{p}$ and the lateral pole of the flocculus with the compartments $\mathrm{FC}_{1-3}$. Small white arrows in $\mathrm{A}, \mathrm{B}$, and $\mathrm{C}$ indicate the $\mathrm{AChE}$-positive raphes bordering the $\mathrm{C}_{2}, \mathrm{FC}_{1}$, and $\mathrm{FC}$ compartments. B: More medial section. The incipient floccular peduncle is separated from compartments $\mathrm{FC}_{1}, \mathrm{FC}_{2}$ and $\mathrm{C}_{2}$ in the white matter of the flocculus by a densely AChE-stained ridge of small cells $\mathrm{FC}_{3}$ joins the floccular peduncle and $\mathrm{FC}_{4}$ appears in the rostral flocculus. C: Section through the lateral pole of the posterior interposed nucleus. Note densely stained ridge of small cells ( $\mathrm{r}$ ) dorsal to the parvicellular lateral nucleus. D: Higher magnification of the floccular peduncle and the ventral and dorsal group $\mathrm{y}$. The floccular peduncle is divided into the AChE-rich bundle of Löwy and a rostral, AChE-poor portion, which contains the neurons of dorsal group $\mathrm{y}$. The scale bar in $\mathrm{B}$ also applies to $\mathrm{A}$ and $\mathrm{C}$. 
Strong staining for $\mathrm{AChE}$, with the highest reactivity in patches between less reactive granule cells, is observed in the entire granular layer of the flocculus and folium $\mathrm{p}$. The deep stratum of the molecular layer also reacts intensely for AChE, but this staining extends beyond the flocculus and folium $p$ to include (by our definition) the entire ventral paraffocculus. Strong staining of the granular layer is also observed in the cortex of the vermis at the bottom of the fissures. This staining extends farther apically in the ventral part of the anterior lobe and in lobule $X$ and ventral lobule IX of the caudal vermis. In other parts of the cerebellum staining is most intense in the superficial granular layer, next to the Purkinje cells, which are always unstained. AChE is also present in the deep stratum of the molecular layer of the vermis, the hemisphere of the anterior lobe, and the simple and paramedian lobules. More laterally, the molecular layer of the hemisphere, including the ansiform lobule and the entire dorsal paraflocculus, is entirely AChE-negative.

According to many authors, the patchy distribution of $\mathrm{AChE}$ in the granular layer is due to staining of cerebellar glomeruli and Golgi cells (Gerebtzoff, 1959; Csillik et al., 1963; Altman and Das, 1970; Brown and Palay, 1972). Glomerular staining for $\mathrm{AChE}$ may be indicative of cholinergic transmission because mossy fiber rosettes immunoreactive to cholineacetyltransferase (ChAT, the synthesizing enzyme of acetylcholine) were found in the granular layer in rat, guinea pig, cat, rabbit, monkey, and human (Kan et al., 1978, 1980; Ojima et al., 1989; Illing, 1990; Ikeda et al., 1991; Barmack et al., 1992a; De Lacalle et al., 1993). In the rat, a plexus of thin, beaded ChAT-immunoreactive fibers pervades all layers of the cortex. ChAT-immunoreactive mossy fibers were mostly restricted to lobule $\mathrm{X}$, ventral lobule IX, and the flocculus (Ojima et al., 1989; Barmack et al., 1992a). A plexus of beaded ChAT-immunoreactive fibers could not be detected in the cerebellum of rabbit. In this species, ChAT-containing mossy fibers were present in lobules I and II of the anterior lobe and the parts of lobules $\mathrm{X}$ and IX facing the posterolateral fissure. They were rather scarce in the flocculus, but the ventral paraflocculus of rabbit was densely innervated (Barmack et al., 1992a).

The resemblance between the distribution of the vestibulocerebellar mossy fiber projections (Thunnissen et al, 1989; Gerrits et al., 1989; Epema et al., 1990; Tan and Gerrits, 1992) and the regions with strong AChE reactivity of the granular layer in the rabbit is very close. Barmack et al. (1992b) traced the cholinergic mossy fiber projections to lobules X and IX and the flocculus in rat and rabbit from ChAT-immunoreactive neurons in the caudal MV and the nucleus prepositus hypoglossi with a double-labeling horseradish peroxidase (HRP) retrograde axonal transportimmunohistochemical technique. The projection to the PFLv of the rabbit originated from ChAT-immunoreactive cells in the nucleus prepositus hypoglossi.

AChE staining of the molecular layer is more variable among species and is therefore more difficult to interpret (Friede and Fleming, 1964; Silver, 1967, 1974; Karczmar, 1969; Marani and Voogd, 1977; Marani, 1982, 1986; Hess and Voogd, 1986). The presence of AChE in the deep stratum of the molecular layer of the flocculus and PFLv and its absence (by definition) in the PFLd of the rabbit does not appear to be related to the distribution of cholinergic terminals, which could not be demonstrated in the molecular layer of the rabbit cerebellum (Barmack et al., 1992a). The AChE-positive displaced Golgi cells of Ramón y
Cajal (1911) and Spaçek et al. (1973) cannot be responsible for the differential distribution of AChE over the molecular layer of the PFLv and PFLd of the rabbit cerebellum, because these cells are distributed ubiquitously over the cortex. Some ChAT-immunoreactive Golgi cells were found in the cat (Illing, 1990; Ikeda et al., 1991) but were not observed in the rabbit (Kan et al., 1978; Barmack et al., 1992a).

\section{Compartmental subdivision of the white matter of the flocculus}

An $\mathrm{AChE}$ subdivision of the cerebellar white matter has previously been observed in the anterior lobe of the cat (Voogd et al., 1986) and in the cerebellum of the monkey, including the flocculus and paraflocculus (Hess and Voogd, 1986; Voogd et al., 1986, 1987). Both in the cerebellum of cat and monkey and in the flocculus of the rabbit, the AChE-positive fiber bundles correspond to accumulations of thin myelinated fibers (raphes) in Häggqvist-stained sections. Raphes usually separate bundles of coarser Purkinje cell axons arising from longitudinal cortical zones on their way from the cortex to their target nuclei. AChE staining of the white matter of the flocculus shows characteristic differences among the compartments. Compartment $\mathrm{FC}_{2}$ is relatively deficient in $\mathrm{AChE}$, especially medially where large-diameter fibers accumulate. The other compartments, particularly the $\mathrm{C}_{2}$ compartment, stain more intensely. The nature of the AChE-positive fibers of the raphes remains puzzling. They may represent $\mathrm{AChE}$ positive mossy fibers, which have become concentrated at the borders of sheets of Purkinje cell axons with different destinations. A possible correlation between concentrations of AChE-positive mossy fiber rosettes in the granular layer and the presence of fascicles of strongly stained fibers in the white matter was noticed by Boegman et al. (1988) for the vermis and paravermis of the rat cerebellum, but the subdivision of the white matter into compartments is not reflected in a zonal distribution of $\mathrm{AChE}$ over the cortex of the flocculus and the paraflocculus. These authors also described a close correspondence between the localization of bands of MAB-Q113-immunoreactive Purkinje cells and the zonal AChE pattern. MAB-Q113-positive Purkinje cells in the rabbit flocculus, however, are distributed rather uniformly (Tan et al., 1989). Moreover, MAB-Q113 immunoreactivity was absent from the axons of Purkinje cells in the white matter of the flocculus. Another factor that may determine the staining of the raphes of the flocculus is their invasion by small, strongly AChE-positive cells. Concentrations of such cells are found as a ridge at the lateral border of the floccular peduncle, where it separates from the flocculus, and also as strongly AChE-reactive patches, dorsal to the parvicellular lateral cerebellar nucleus. The scattered, AChE-positive cells in the white matter of the flocculus may correspond to part of the basal interstitial nucleus of primates (Langer, 1985). The AChE-positive neurons of the floccular white matter and group $y$ of the rat are ChAT negative (Komei et al., 1983).

Four compartments were tentatively identified in the white matter of the flocculus and the PFLv in macaques (Hess and Voogd, 1986; Voogd et al., 1987). In both the monkey and the rabbit the most lateral $\mathrm{C}_{2}$ compartment extends into the paraflocculus and includes the posterior interposed nucleus. No equivalent of compartment $\mathrm{FC}_{4}$ was found in primates. 


\section{Longitudinal zones in the cortex of the flocculus}

Anatomical as well as physiological studies have indicated the presence of longitudinal zonation in the flocculus. In an anterograde tracing study in the cat Gerrits and Voogd (1982) showed that climbing fibers from the dorsal cap and the adjoining ventrolateral outgrowth, the bend of the principal olive, and the rostral pole of the medial accessory olive terminate in longitudinal strips in the molecular layer. In the flocculus they observed seven climbing fiber zones (F1-F6 and $\mathrm{C}_{2}$ ) in the molecular layer derived from different parts of the inferior olive. An additional zone (F7) was observed in the adjacent PFLv. The fibers travelled in bundles in adjacent longitudinal white matter compartments. However, they did not correlate the location of these fiber bundles with matching $\mathrm{AChE}$ - or Häggqvist-stained material. A lateral $\mathrm{C}_{2}$ zone receiving climbing fibers from the rostral pole of the medial accessory olive was clearly present in the cat, and the fusion in the PFLv of the F2+3 and the F5 $+6+7$ zones around F4 (a zone that receives climbing fibers from the caudal part of the dorsal cap; Gerrits and Voogd 1982) may correspond to the fusion of compartments $\mathrm{FC}_{1}$ and $\mathrm{FC}_{3}$ in folium $\mathrm{p}$ of the rabbit. The topographical relations of the five climbing fiber zones that were traced by Ruigrok et al. (1992) with anterograde axonal transport of Phaseolus vulgaris lectin to the flocculus and the paraflocculus of the rat closely resemble the compartmentation of $\mathrm{AChE}$ in the flocculus of the rabbit. A $\mathrm{C}_{2}$ zone, innervated from the rostral pole of the medial accessory olive, is present in the lateral and caudal region of the flocculus. The dorsal cap and the ventrolateral outgrowth each project to two discrete zones in the flocculus of the rat. ${ }^{2}$ The $F D$ and $\mathrm{FD}^{\prime}$ zones receive their climbing fibers from the ventrolateral outgrowth. They continue in the PFLv, where they are innervated by the ventral leaf of the principal olive. Two other zones ( $\mathrm{FE}$ and $\mathrm{FE}^{\prime}$ ) receive climbing fibers from the dorsal cap. The $\mathrm{FE}^{\prime}$ zone is found at the rostral pole of the flocculus and does not extend into the PFLv; it may correspond to $\mathrm{FC}_{4}$ of the rabbit flocculus. The FE zone continues for a short distance into the PFLv, where the FD and FD' zones fuse around it. This fusion can be considered as the equivalent of the fusion of $\mathrm{FC}_{1}$ and $\mathrm{FC}_{3}$ around $\mathrm{FC}_{2}$ in folium $\mathrm{p}$ of the rabbit.

The observations of Yamamoto and Shimoyama (1977) on Purkinje cell zones in the flocculus and folium $p$ of the rabbit are very similar to our observations on compartments, with respect to number and extent. Originally Yamamoto and Shimoyama (1977) distinguished two pairs of Purkinje cell zones that were retrogradely labeled from the MV and the superior vestibular nucleus, respectively. The two Purkinje cell zones projecting to the MV were interleaved with the two zones projecting to the superior vestibular nucleus. The most rostromedial of these four zones projected to the MV. In later papers by Yamamoto $(1978,1979 a, b)$ the existence of the more rostral of the two zones projecting to the MV was ignored. Purkinje cells in

${ }^{2}$ The dorsal cap and the ventrolateral outgrowth are segments from a continuous cell column. Rostrally this column is continuous with the principal olive. The morphological and functional criteria used to subdivide this cell column are discussed by Tan et al. (1995a). In the rabbit and the cat the column is subdivided into two subnuclei, which comprise the cauda dorsal cap and the rostral dorsal cap with the ventrolateral outgrowth. In the rat these two subnuclei correspond to the dorsal cap and the ventrolateral outgrowth. the caudal fiocculus projected to the lateral cerebellar nucleus and those from an intermediate region of folium $p$ to the nucleus prepositus hypoglossi (Yamamoto, 1978).

Sato et al. (1982a,b) distinguished three Purkinje cell zones in the flocculus of the cat: a rostral zone projecting to the superior vestibular nucleus, a middle zone projecting to the MV, and a caudal zone projecting to group $y$ and the parvicellular part of the lateral cerebellar nucleus. Three similar, if not identical, zones received projections from the rostral dorsal cap and ventrolateral outgrowth (rostral and caudal zones), and the caudal dorsal cap (middle zone; Sato et al., 1983). Some of the findings of Sato et al. (1982a,b, 1983) and Yamamoto (1978) are difficult to reconcile with the data from our study on the subdivision of the rabbit flocculus and with the detailed analysis of the olivocerebellar projection to the cat flocculus by Gerrits and Voogd (1982). Neither Yamamoto (1978) nor Sato et al. (1982b) reported a zone corresponding to the floccular $\mathrm{C}_{2}$ zone found in the present study to be related to the posterior interposed nucleus. Instead, they advocated a projection to the lateral cerebellar nucleus from Purkinje cells in this region. Their injections of the lateral cerebellar nucleus, however, may have included the posterior interposed nucleus. Yamamoto (1979a) did, however, report a projection from the rostral pole of the MAO to the caudal flocculus in the rabbit, in accordance with the presence of the $\mathrm{C}_{2}$ zone in this region.

Yamamoto and Shimoyama (1977), Yamamoto (1978, 1979a), Gerrits and Voogd (1982), and Ruigrok et al. (1992), traced Purkinje cell and climbing fiber zones from the flocculus into the adjoining part of the PFLv. Gerrits and Voogd (1982) found an extension of the climbing fiber zones from the dorsal cap, the ventrolateral outgrowth, and the MAO into their medial extension (ME) of the PFLv and an exclusive projection of the principal olive to the ME and other parts of the PFLv. Similar connections from the dorsal cap, ventrolateral outgrowth, and caudal principal olive were described by Yamamoto $(1978,1979$ a) for folium $\mathrm{p}$ of the rabbit cerebellum and by Ruigrok et al. (1992) for the PFLv of the rat. We found that compartments $C_{2}$ and $\mathrm{FC}_{1-3}$ extended into the white matter of folium p. $\mathrm{FC}_{2}$ and $\mathrm{FC}_{3}$ were represented only in the rostral pole of folium $\mathrm{p}$. $\mathrm{FC}_{4}$ did not enter this folium.

\section{Group y and the parvicellular lateral cerebellar nucleus}

Group y can be considered the bed nucleus of the floccular peduncle. Unfortunately, a definition of this cell group that can be applied to all species is lacking. Brodal and Pompeiano (1957) first described it as a subgroup of the vestibular nuclei of the cat, containing small cells, and capping the restiform body dorsally. It was described as situated between Deiters' nucleus medially and the cochlear nucleus laterally with scattered cells connecting it with the lateral cerebellar nucleus. Group y of the cat was further subdivided by Gacek (1977, 1979) and Highstein and Reisine (1979). Highstein and Reisine (1979) distinguished a dorsal group $y$, located within the floccular peduncle where it arches over the restiform body (corresponding to the infracerebellar nucleus of Gacek) from the more ventrally located, small and tightly packed cells of ventral group y (corresponding to group y of Gacek). The two nuclei differed in their connections; dorsal group y projected to the oculomotor nucleus, while ventral group y was part of the commissural vestibular system. No descrip- 
tions of group $y$ are available for the rabbit. We distinguished dorsal and ventral subdivisions of group $\mathrm{y}$ in $\mathrm{AChE}$-reacted material of the rabbit. Ventral group $y$ corresponds to the densely AChE-stained parvicellular layer that caps the restiform body. Dorsal group y consists of larger, AChE-positive cells scattered among the fibers of the floccular peduncle and invading the Lpc. As a consequence Epema et al. (1988, 1990), Gerrits et al. (1989), Thunnissen (1990), and De Zeeuw et al. (1994) included a variable portion of the $L p c$ of the rabbit in their group $y$. 'The position of the Lpc in rabbit corresponds to that of the parvicellular part of the lateral cerebellar nucleus of the rat (Korneliussen, 1968; Voogd et al., 1985; Ruigrok and Voogd, 1990). Medially both group y and the Lpc merge with the AChE-positive caudal pole of the superior vestibular nucleus, which was indicated as a separate subnucleus (group 1) by Brodal and Pompeiano (1957) in the cat. In our subdivision of the cerebellar nuclei we closely followed Ono and Kato (1938). The main divergence from these authors is the identification of the "pars a" of the posterior interposed nucleus of Ono and Kato (1938) and also of Van Rossum (1969), as the dorsolateral protuberance of the fastigial nucleus, first described by Goodman et al. (1963) in the rat.

The explanation for the presence of AChE at the borders of white matter compartments of the rabbit flocculus and paraflocculus still eludes us, but as an independant method of reliably subdividing that part of the cerebellum it has proved useful to correlate the connections, immunohistochemistry, and electrophysiology of the rabbit flocculus (Tan et al., 1989, 1995a,b; Van der Steen et al., 1991, 1994; Simpson et al., 1992).

\section{ACKNOWLEDGMENTS}

This research was supported in part by NIH grant NS-13742. J.I. Simpson held the Tinbergen Professorship at Erasmus University Rotterdam during part of this research. The technical assistance of R.C. Boer, J. v.d. Burg. E. Dalm, E. Goedknegt, and F.H. Klink, and the secretarial help of E. Klink are gratefully acknowledged.

\section{LITERATURE CITED}

Altman, J., and G.D. Das (1970) Postnatal changes in the concentration and distribution of cholinesterase in the cerebellar cortex of rats. Exp. Neurol. 28:11-34.

Andersson, G., and O. Oscarsson (1978a) Projections to lateral vestibular nucleus from cerebellar climbing fiber zones. Exp. Brain Res. 32:549 564

Andersson, G., and O. Oscarsson (1978b) Climbing fiber microzones in the cerebellar vermis and their projection to different groups of cells in the lateral vestibular nucleus. Exp. Brain Res. 32:565-579.

Appleyard, M., and H. Jahnsen (1992) Actions of acetylcholinesterase in the guinea pig cerebellar cortex in vitro. Neuroscience 47:291-301.

Barmack, N.H., R.W. Baughman, and F.P. Eckenstein (1992a) Cholinergic innervation of the cerebellum of rat, rabbit, cat, and monkey as revealed by choline acetyltransferase activity and immunohistochemistry. J. Comp. Neurol. 317:233-249.

Barmack, N.H., R.W. Baughman, F.P. Eckenstein, and H. Sojaku (1992b) Secondary vestibular cholinergic projection to the cerebellum of rabbit and rat as revealed by choline acetyltransferase immunohistochemistry. J. Comp. Neurol. 317:250-270.

Barth, F., and M.S. Ghandour (1983) Cellular localization of butyrylcholinesterase in adult rat cerebellum determined by immunofluorescence. Neurosci. Lett. 39:149-153.

Bernard, J.F. (1987) Topographical localization of olivocerebellar and corticonuclear connections in the rat-A WGA-HRP study. I. Lobules IX, X, and the flocculus. J. Comp. Neurol. 263:241-258.
Bigaré, F. (1980) De efferente verbindingen van de cerebellaire schors van de kat. 'Thesis, Leiden, The Netherlands: University of Leiden.

Boegman, R.J., A. Parent, and R. Hawkes (1988) Zonation in the rat cerebellar cortex: Patches of high acetylcholinesterase activity in the granular layer are congruent with Purkinje cell compartments. Brain Res. 448:237-251.

Bolk, L. (1906) Das Cerebellum der Säugetiere: Eine vergleichende anatomische Untersuchung. Jena/Haarlem: Fischer.

Brodal, A. (1940) The cerebellum of the rabbit. A topographical atlas of the folia as revealed in transverse sections. J. Comp. Neurol. 72:63-81.

Brodal, A., and O. Pompeiano (1957) The vestibular nuclei in the cat. J. Anat. 91:438-454

Brodal, A, and K. Kawamura (1980) Olivocerebellar projection: A review, Adv. Anat. Embryol. Cell Biol. 64:1-137.

Brown, W.J., and S.L. Palay (1972) Acetylcholinesterase activity in certain glomeruli and Golgi cells of the granular tayer of the rat cerebellar cortex. Z. Anat. Entwickl. Gesch. 137:317-334

Chan-Palay, V., G. Nilaver, S.L. Palay, M.C. Beinfeld, E.A. Zimmerman, J.Y. Wu, and T.L. O'Donohue (1981) Chemical heterogeneity in cerebellar Purkinje cells: Existencc and coexistence of glutamic acid decarboxylaselike and motilin-like immunoreactivities. Proc. Natl. Acad. Sci. U.S.A. $78: 7787-7791$

Chan-Palay, V., S.L. Palay, and J.Y. Wu (1982). Sagittal cerebellar microbands of taurine neurons: Immunocytochemical demonstration by using antibodies against the taurine synthesizing enzyme cysteine sulfinic acid decarboxylase. Proc. Natl. Acad. Sci. U.S.A. 79:4221-4225.

Courville, J., F. Faraco-Cantin, and N. Diakiw (1974) A functionally important feature of distribution of the olivocerebellar climbing fibers. Can. J. Physiol. Pharmacol. 52:1212-1217.

Csillik, B., F. Joo, and P. Kasa (1963) Cholinesterase activity of archicerebellar mossy fiber apparatus. J. Histochem. Cytochem. 11:103-113.

De Lacalle, S., L.B. Hersh, and C.B. Saper (1993) Cholinergic innervation of the human cerebellum. J. Comp. Neurol. 328:364-376.

Deiters, O. (1865) Untersuchungen üher Gehirn und Rückenmark. Braunschweig.

De Zeeuw, C.I., N.M. Gerrits, J. Voogd, C.S. Leonard, and J.I. Simpson (1994) The rostral dorsal cap and ventrolateral outgrowth of the rabbit inferior olive receive a GABAergic input from dorsal group $Y$ and the ventral dentate nucleus. J. Comp. Neurol. 341:420-432

Epema, A.H., N.M. Gerrits, and J. Voogd (1988) Commissural and intrinsic connections of the vestibular nuclei in the rabbit: A retrograde tracer study. Exp. Brain Res. 71:129-146.

Epema, A.H., N.M. Gerrits, and J. Voogd (1990) Secondary vestibulocerebellar mossy fiber projections to the flocculus and uvulonodular lobule in the rabbit: A study using HRP and double fluorescent tracer techniques. Exp. Brain Res. 80:72-82.

Friede, R.L., and L.M. Fleming (1964) A comparison of cholinesterase distribution in the cerebellum of several species. J. Neurochem. 11:1-7.

Fuse, G. (1912) Die innere Abteilung der Kleinhirnstiels (Meynert, I.A.K.) und der Deiterssche Kern. Arb. Hirnanat. Inst. Zürich 6:29-267.

Gacek, R.R. (1977) Location of brain stem neurons projecting to the oculomotor nucleus in the cat. Exp. Neurol. 57:725-749.

Gacek, R.R. (1979) Location of abducens afferent neurons in the cat. Exp. Neurol. 64:342--353.

Geneser-Jensen, F.A., and T.W. Blackstad (1971) Distribution of acetylcholinesterase in the hippocampal region of the guinea-pig. I. Entorhinal area, parasubiculum and presubiculum. Z. Zellforsch. Mikrosk. Anat. $174: 460-481$

Gerebtzoff, M.A. (1959) Cholinesterases: A Histochemical Contribution to the Solution of Some Functional Problems. International Series of Monographs on Pure and Applied Biology, Vol. 3. Oxford: Pergamon Press.

Gerrits, N.M., and J. Voogd (1982) The climbing fiber projection to the flocculus and adjacent paraflocculus in the cat. Neuroscience $7: 2971$ 2991

Gerrits, N.M., and J. Voogd (1989) 'The topographical organism of elimbing and mossy fiber afferents in the flocculus and the ventral paraflocculus in rabbit, cat and monkey. In P. Strata (ed): The Olivocerebellar System in Motor Control. Exp. Brain Res. Series, Vol. 17. Amsterdam: Elsevier, pp. 26-29.

Gerrits, N.M., A.H. Epema, A. van Linge, and E. Dalm (1989) The primary vestibulocerebellar projection in the rabbit: Absence of primary afferents in the flocculus. Neurosci. Lett. 290:262-277. 
Goodman, D.C. R.E. Hallett, and R.B. Welch (1963) Patterns of localization in the cerebeliar cortico-nuclear projection of the albino rat. J. Comp. Neurol. 121:51-67.

Gorenstein, C., N.C. Bundman, J.L. Bruce, and A. Rotter (1987) Neurona localization of pseudocholinesterase in the rat cerebellum: Sagittal bands of Purkinje cells in the nodulus and uvula. Brain Res. 418:68-75.

Greenfield, S.A. (1984) Acetylcholinesterase may have novel functions in the brain. Trends Neurosci. 7:364-368.

Groenewegen, H.J., and J. Voogd (1977) The parasagittal zonation within the olivocerebellar projection. I. Climbing fiber distribution in the vermis of the cat cerebellum. J. Comp. Neurol. 174:417-488.

Groenewegen, H.J., J. Voogd, and S.L. Freedman (1979) The parasagittal zonation within the olivocerebellar projection. II. Climbing fiber distribution in the intermediate and hemispheric parts of the cat cerebellum. $J$ Comp. Neurot. 183:551-602.

Häggqvist, G. (1936) Analyse der Faserverteilung in einem Rückenmarkquerschnitt (Th. 3). Z. Mikrosk. Anat. Forschung 29:1-34.

Hawkes, $R$., and $N$. Leclerc (1987) Antigenic map of the rat cerebellum: Distribution of parasagittal bands as revealed by monoclonal antiPurkinje cell antibody mabQ113. J. Comp. Neurol. 256:29 41.

Hess, D.T., and J. Voogd (1986) Chemoarchitectonic zonation of the monkey cerebellum. Brain Res. 369:383-387.

Highstein, S.M., and H. Reisine (1979) Svnaptic and functional organization of vestibulo-ocular reflex pathways. Prog. Brain Res. 50:431-442.

Ikeda, M., T. Houtani, T. Leyama, and T. Sugimoto (1991) Choline acetyltransferase immunoreactivity in the cat cerebellum. Neuroscience 45:671-690.

Illing, R.-B. (1990) A subtype of cerebellar Golgi cells may be cholinergic Brain Res. 522:267-274.

Ingram, V.M., M.P. Ogren, C.L. Chatot, J.M. Gossels, and B. B. Owens (1985) Diversity among Purkinje cells in the monkey cerebellum. Proc. Natl Acad. Sci. L.S.A. 82:7131-7135.

Kan, K.S.K., L.P. Chao, and L.S. Forno (1978) Immunohistochemical localization of choline acetyltransferase in rabbit spinal cord and cerebellum. Brain Res. 146:221-229.

Kan, K.S.K., L.P. Chao, and L.S. Forno (1980) Immunohistochemica localization of choline acetyltransferase in the human cerebellum. Brain Res, 193:165-171.

Karczmar, A.G. (1969) Is the central cholinergic nervous system overex ploited? Fed. Proc. Fed. Am. Soc. Exp. Biol. 28:147-157.

Komei, I., T. Hajai, P.L. McGeer, and E.G. McGeer (1983) Evidence for an intracerebellar acetylcholinesterase-rich but probably non-cholinergic flocculonodular projection in the rat. Brain Res. 258:115-119.

Korneliussen, H.K. (1968) On the ontogenic development of the cerebellum (nuclei, fissures, and cortex) of the rat, with special reference to regional variations in corticogenesis. J. Hirnforsch. 10:379-412.

Langer, T. (1985) Basal interstitial nucleus of the cerebellum: Cerebellar nucleus related to the flocculus. J. Comp. Neurol. 235:38-47.

Larsell, O. (1937) The cerebellum, a review and interpretation. Arch. Neurol. Psychiatr. 38:580-607.

Larsell, $O$. (1970) 'The comparative anatomy and histology of the cerebellum from Monotremes through Apes. In: The Human Cerebellum Connections and 'The Cerebellar Cortex. Minneapolis: University of Minnesota Press, $269 \mathrm{pp}$.

Lorente de Nó, R. (1933) Anatomy of the eighth nerve. Laryngoscope 43:1-38.

Löwy, R. (1928) Über die Faseranatomie und Physiologie der Formatio vermicularis cerebelli. Arb. Neurol. Inst. Univ. Wien. 21:359-382.

Marani, E. (1982) Topographic enzyme histochemistry of the mammalian cerebellum $5^{\prime}$-nucleotidase and acetylcholinesterase. Thesis. Leiden, The Netherlands: University of Leiden.

Marani, E. (1986) Topographic histochemistry of the cerebellum. Prog. Histochem. Cytochem. 16:1-169.

Marani, E., and .J. Voogd (1977) An acetylcholinesterase bandpattern in the molecular layer of the cat cerebellum. J. Anat. 124:335-345.

Nilaver, G., R. Defendini, K.A. Zimmerman, M.C. Beinfeld, and T.L. O'Donohue (1982) Motilin in the Purkinje cell of the cerebellum. Nature 295:597-598.

Ogawa, T. (1935) Beiträge zur vergleichenden Anatomie des Zentralnervensystems der Wassersäugetiere. Ueber die Kleinhirnkerne der Pinnipedian und Cetaceen. Arb. Anat. Inst. Sendai 17:63-136.

Ojima, H., S.-I. Kawajiri and T. Yamasaki (1989) Cholinergic innervation of the rat cerebellum: Qualitative and quantitative analyses of elements immunoreactive to a monoclonal antibody against choline acetyltransferase. J. Comp. Neurol. 290:41-52.
Ono, M., and H. Kato (1938) Zur Kenntnis des Kleinhirnkerne des Kaninchens. Anat. Anz. 86:245-259.

Oscarsson $O$ (1973) Functional organization of spinocerebellar paths. In A. Iggo (ed): Handbonk of Sensory Physiology. Vol. III. Somatosensory System. New York: Springer, pp. 339-380.

Ramón y Cajal, S. (1911) Histologie du Système Nerveux de l'Homme et de Vertebres. Vol. II. Paris: Maloine, p. 24.

Robertson, I.T., and K. Logan (1986) Relationship of parasagittal bands of acetylcholinesterase activity to the climbing fiber representation. Neurosci. Lett. 72:128-134

Ruigrok, T.J.H., and J. Voogd (1990) Cerebellar nucleo-olivary projections in the rat: An anterograde tracing study with Phaseolus vulgarisleucoagglutinin (PHA-L), J. Comp. Neurol. 298:315-333.

Ruigrok, T.J.H., R.J. Osse, and J. Voogd (1992) Organization of inferior olivary projections to the flocculus and ventral paraflocculus of the rat cerebellum. J. Comp. Neurol. 316:129-150.

Sato, Y., T. Kawasaki, and K. Ikarashi (1982a) Zonal organization of the floccular Purkinje cells projecting to the vestibular nucleus in cats. Brain Res. 232:1-15.

Sato, Y., 'T. Kawasaki, and K. Ikarashi (1982b) Zonal organization of the floccular Purkinje cells projecting to the group $y$ of the vestibular complex and the lateral cerebellar nucleus in cats. Brain Res. 234:430 434.

Sato, Y., T. Kawasaki, and K. Ikarashi (1983) Afferent projections from the brainstem to the three floccular zones in cats. I. Climbing fiber projections. Brain Res. 272:27-36.

Scott, T.G. (1963) A unique pattern of localization in the cerebellum. Nature 200:793.

Scott, T.G. (1964) A unique pattern of localization within the cerebellum of the mouse. J. Comp. Neurol. 122:1-8.

Silver, A. (1967) Cholinesterases of the central nervous system with special reference to the cerebellum. Int. Rev. Neurobiol. 10:57-109.

Silver, A. (1974) The Biology of Cholinesterases. Amsterdam: Elsevier, pp. 355-388.

Simpson, J.I, J. Van der Steen, and J. Tan (1992) Eye movements and the zonal structure of the rabbit flocculus. In R. Llinás and C. Sotelo (eds): The Cerebellum Revisited. New York: Springer-Verlag, pp. 255-266

Spaçek, J., L. Parizek, and A.R. Lieberman (1973) Golgi cells, granule cells and synaptic glomeruli in the molecular layer of the rabbit cerebellar cortex. J. Neurocytol. 2:407-428.

Stroud, B.B. (1895) The mammalian cerebellum. J. Comp. Neurol. 5:71-118.

Tan, H., and N.M. Gerrits (1992) Laterality in the vestibulo-cerebellar mossy fiber projection to flocculus and caudal vermis in the rabbit: A retrograde fluorescent double-labeling study. Neuroscience 47:909-919.

Tan, J., L.M. Eisenman, N.M. Gerrits, R. Hawkes, and J. Voogd (1989) Compartmentalization within the rabbit flocculus. A mab $Q 113$ immunohistochemical, acetylcholinesterase and anatomical tracing study. Eur. J. Neurosci. Suppl. 2:33.

Tan, J., N.M. Gerrits, R.S. Nanhoe, J.I. Simpson, and J. Voogd (1995a) Zonal organization of the climbing fiber projection to the floceulus and nodulus of the rabbit. A combined axonal tracing and acetylcholinesterase study. J. Comp. Neurol. 356:23-50.

Tan, J., A. Epema, and J. Voogd (1995b) Zonal organization of the flocculovestibular nucleus projection in the rabbit. A combined axonal tracing and acetylcholinesterase histochemical study. J. Comp. Neurol. $356.51-71$.

Thunnissen, I.E. (1990) Vestibulocerebellar and vestibulo-oculomotor relations in the rabbit. Thesis, Rotterdam.

Thunnissen, I.E., A.H. Epema, and N.M. Gerrits (1989) Secondary vestibulocerebellar mossy fiber projection to the caudal vermis in the rabbit. J. Comp. Neurol. 290:262-277.

Trott, J.R., and D.M. Armstrong (1987a) The cerebellar corticonuclear projection from lobule $\mathrm{Vb} / \mathrm{c}$ of the cat anterior lobe: A combined electrophysiological and autoradiographic study. I. Projection from the intermediate region. Exp. Brain Res. 66:318-338.

Trott, J.R., and D.M. Armstrong (1987b) The cerebellar corticonuclear projection from lobule $\mathrm{Vb} / \mathrm{c}$ of the cat anterior lobe: A combined electrophysiological and autoradiographic study. II. Projection from the vermis. Exp. Brain Res, 68:339-358.

Van der Schueren, A. (1912) Etude anatomique du faisceau longitudinal postérieur. Nevraxe 13:183-309.

Van der Steen, J., J.I. Simpson, and J. Tan (1991) Representation of three-dimensional eye movements in the cerebellar floceulus of the rabbit. In R. Schmid and D. Zambarbieri (eds): Oculomotor Control and Cognitive Processes. Amsterdam: Elsevier, pp. 63-77. 
Van der Steen, J., J.I. Simpson, and J. Tan (1994) Functional and anatomic organization of three-dimensional eye movements in rabbit cerebellar flocculus. J. Neurophysiol. 72:31-46.

Van Gehuchten A. (1904) Connexions centrales du noyeau de Deiters et des masses grises voisines. Nevraxe 6:21-73.

Vun Rossum, J. (1969) Corticonuclear and corticovestibular projections of the cerebellum. Thesis. Leiden, The Netherlands: University of Leiden. Assen: Van Gorcum.

Voogd, J. (1964) The Cerebellum of the Cat. Thesis. Leiden, The Netherlands: University of Leiden.

Voogd, J. (1969) The importance of fibre connections in the comparative anatomy of the mammalian cerebellum. In R. Llínas (ed): Neurobiology of Cerebellar Evolution and Development, Chicago: A.M.A., pp. 493-514.

Voogd, J. (1975). Bolk's subdivision of the mammalian cerebellum. Growth centres and functional zanes. Acta Morphol. Neerl. Scand. 13:35-54.

Voogd, .J. (1982) The olivocerebellar projection in the cat. In S.L. Palay and V. Chan-Palay (eds): The Cerebellum: New Vistas. New York: SpringerVerlag, pp. 135-161.

Voogd, J. (1989). Parasagittal zones and compartments of the anterior vermis of the cat cerebellum. In P. Strata (ed): The Olivocerebellar System in Motor Control. Exp. Brain Res. Suppl. 17. New York: Springer-Verlag, pp 3-19.

Voogd, J., and F. Bigaré (1980) Topographical distribution of olivary and corticonuclear fibers in the cerebellum. A review. In J. Courville, C.C. de Montigny, and Y. Lamarre (eds): The Inferior Olivary Nucleus: Anatomy and Physiology. New York: Raven Press, pp. 207-234.

Voogd, J., and H.K.P. Feirabend (1981) Classic methods in neuroanatomy In R. Lahue (ed): Methods in Neurobiology. Vol. 2. New York: Plenum, pp. 301-365.
Voogd, J., N.M. Gerrits, and E. Maranj (1985) The cerebellum of the rat. In G. Paxinos (ed): The Rat Nervous System. Vol. 2. Hindbrain and Spina! cord. London: Academic Press, pp. 251-291.

Voogd, J., N.M. Gerrits, and D.T. Hess (1986) Parasagittal zonation of the cerebellum in macaques: An analysis based on acetylcholinesterase histochemistry. In M. Glickstein, C. Yeo, and J. Stein (eds): Cerebellum and Neuronal Plasticity. New York: Plenum, pp. 15-39.

Voogd, J., D.T. Hess, and E. Marani (1987) The parasagittal zonation of the cerebellar cortex in cat and monkey. In J.S. King (ed): New Concepts in Cerebellar Neurobiology, Neurology and Neurobiology. Vol. 22. New York: Alan R. Liss Inc., pp. 183-220.

Weidenreich, F. (1899) Zur Anatomie der zentralen Kleinhirnkerne der Säuger. Z. Morphol. Anthropol. 1:259-312

Yamamoto, M. (1978) Localization of rabbit's flocculus Purkinje cells projecting to the lateral cerebellar nucleus and the nucleus prepositus hypoglossi investigated by means of the horseradish peroxidase retrograde axonal transport. Neurosci. Lett. 7:197-202.

Yamamoto, M. (1979a) Topographical representation in rabbit cerebellar flocculus for various afferent inputs from the brainstem investigated by means of retrograde axonal transport of horseradish peroxidase. Neurosci. Lett. 12:29-34.

Yamamoto, M. (1979b) Vestibulo-ocular reflex pathways of rabbits and their representation in the cerebellar flocculus. In R. Granit and O. Pompeiano (eds): Reflex Control of Posture and Movement. Prog. Brain Res. 50:451-457. Amsterdam: Elsevier/North-Holland.

Yamamoto, M., and I. Shimoyama (1977) Differential localization of rabbit's flocculus Purkinje cells projecting to the medial and superior vestibular nuclei investigated by means of the HRP retrograde axonal transport. Neurosci. Lett. 5:279-283. 